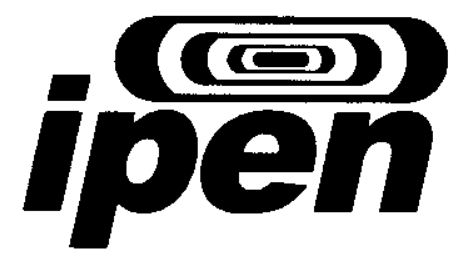

AUTARQUIA ASSOCIADA A UNIVERSIDADE DE SAO PAULO

\title{
ISOLAMENTO E CARACTERIZAÇÃO DA DELTA TOXINA DO \\ VENENO DE Crotalus durissus terrificus
}

\section{LUCÉLIA DE ALMEIDA CAMPOS}

Dissertaçăo apresentada como parte dos requisitos para obtenção do Grau de Mestre em Ciências na Area de Tecnologia Nuclear - Aplicaçð̌es.

Orientador:

Patrick Jack Spencer

São Paulo

2006 


\section{INSTITUTO DE PESQUISAS ENERGÉTICAS E NUCLEARES \\ Autarquia Associada à Universidade de São Paulo}

\section{ISOLAMENTO E CARACTERIZAÇÃO DA DELTA TOXINA DO VENENO DE Crotalus durissus terrificus}

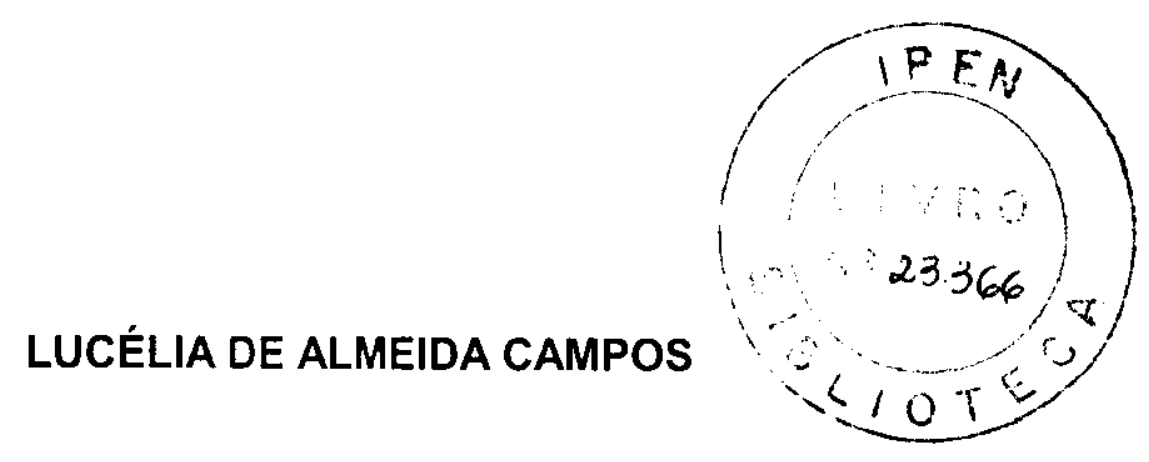

Dissertação apresentada como parte dos requisitos para obtenção do Grau de Mestre em Ciências na Área de Tecnologia Nuclear - Aplicações.

Orientador:

Patrick Jack Spencer

SÃO PAULO

2006 
"São fúteis e cheinc de erros as ciências que não nasceram da :xperimentação, mãe de todo conhecimento"

Leonardo da Vinci 
Aos meus pais, Claudio e Sonia, dedico esse trabalho.

Obrigada pelo apoio incondicional, o amor e toda a força e coragem que me deram para concluir mais essa etapa da minha vida.

Devo tudo a vocês! 


\section{AGRADECIMENTOS}

Agradeço primeiramente a Deus pela proteção e força para trilhar os caminhos da vida.

Aos meus pais. Cláudio e Sonia, pelo total apoio, confiança, dedicação durante todo esse tempo e por dividirem comigo os melhores momentos de minha vida.

Ao meu orientador e amigo Dr. Patrick Jack Spencer, pela amizade, confiança e por compartilhar comigo seus conhecimentos, experiências profissionais e de vida.

Ao meu irmão Marcelo, por estar sempre por perto e me chamar de nerd.

Ao meu namorado André, pelo amor e apoio durante todos esses anos e pela ajuda com o Photoshop.

Á Dra. Maisa Splendore Della-Casa do Instituto Butantan, pelo auxilio nos ensaios de agregação plaquetária, além da grande amiga que ganhei.

À Dra. Ana Moura do Instituto Butantan, pela disponibilização do laboratório e dos equipamentos.

À Dra. Ruth Vassão do Instituto Butantan, muito obrigada pelo apoio, incentivo e principalmente pela relação de amizade que construímos com muitas risadas.

À Dra. Nanci do Nascimento pela ajuda na correção e revisão do trabalho.

Às Dras. Olga Zazuco Higa, Ligia Ely Morganti Ferreira Dias e Maria Aparecida Pires Camilo. obrigada pela ajuda e disponibilização de reagentes e aparelhos.

À Dra. Mirian Camargo Guarnieri da Universidade Federal de Pernambuco, pela amizade e disponibilização de reagentes.

Às amigas Milena e llca da Universidade Federal de Pernambuco, pela ajuda nos experimentos, palavras de apoio e principalmente pela amizade.

Ao Dr. Rui Seabra Ferreira Jr. do Centro de Estudos de Venenos e Animais Peçonhentos de Botucatu, pelo fornecimento do veneno.

Ao Dr. Daniel Pimenta do Instituto Butantan, pela realização da análise de massa. 
Ao Dr. Ivo Lebrun do Instituto Butantan, pelas primeiras tentativas com experimentos de análise de aminoácidos. dados.

À Dra. Esther Ricci. pela ajuda na realização do gel $2 \mathrm{D}$ e discussão dos

A Daniela Nardi, da Universidade Federal de São Paulo. pela ajuda nos ensaios conclusivos de análise de aminoácidos.

Ao amigo Johnny, pela ajuda na padronização nas técnicas de purificação e principalmente pela amizade.

Ao amigo Murilo Casare, obrigada pela ajuda nas cromatografias e principalmente pelos momentos de descontração no laboratório.

À amiga Janaína, pela correção do trabalho, ajuda na bancada e por estar sempre por perto em todos os momentos.

Ao amigo José Alberto "Troxa" da Silva, obrigada pela amizade e momentos de descontração com todas as histórias engraçadas contadas por você.

Ao amigo Júnior, obrigada pelos longos papos sobre mistérios que existem entre o céu e a terra.

Ao amigo Andrés pelas histórias engraçadas e criação de fotos e vídeos comprometedores do pessoal do laboratório. por perto.

Às minhas "irmãs" Fernanda Calvo e Milena, obrigada por estarem sempre

Às amigas, Natália. Daniela, Rosa, Solange, Priscila, muuuuito obrigada pelo apoio e amizade durante todos esses anos.

Às minhas grandes amigas de graduação, Fefa, Patruca, Maricota, Danisbela e Mayra (Cô), muito obrigada pela amizade, apoio e momentos de besteirol!

A todos os funcionários e amigos do IPEN, Dona Ge, Edu. Longino pela manutenção e organização dos laboratórios.

À Neidinha, pelos momentos de risadas na copa.

A CAPES pelo apoio financeiro. 


\section{ISOLAMENTO E CARACTERIZAÇÃO DA DELTA TOXINA DO VENENO DE Crotalus durissus terrificus}

Lucélia de Almeida Campos

\section{RESUMO}

O veneno de $C$. $d$. terrificus tem sido descrito como sendo de pouca complexidade, tendo 4 fraçōes caracterizadas, convulxina, giroxina. crotoxina e crotamina. O presente trabalho visou o isolamento e caracterização da Delta toxina cuja existência havia sido aventada em trabalhos anteriores.

Após a realização de uma varredura de tampões em uma coluna de exclusão molecular Superdex-75 acoplada a um sistema FPLC, na presença de três diferentes tampōes, chegou-se a uma condição ideal de fracionamento do veneno crotálico. Em seqüência realizou-se a segunda etapa de purificação em sistema HPLC em uma coluna $\mathrm{C} 4$, onde foi possivel identificar o pico de interesse. O pico puro passou por análises em MALDI-ToF sendo sua massa estimada em 14.074,92 Da, Quando analisado por eletroforese em gel de poliacrilamida, a delta toxina apresentou massa molecular de cerca de $14 \mathrm{kDa}$ e uma migração anômala, Por eletroforese $2 \mathrm{D}$, a proteína apresentou caráter ácido, com pl entre 4 e 5 e massa molecular de aproximadamente $42 \mathrm{kDa}$, revelando "spots" muito semelhantes podendo ser isoformas com caracteristicas de uma proteina glicosilada. Após digestão dos spots com tripsina, os fragmentos foram confrontados com o banco de dados do "swissprot", mostrando alto grau de homologia "até $43 \%$ de cobertura" com a trocarina, um ativador de protrombina do veneno de Tropidechis carinatus, esses dados foram confirmados com a análise de aminoácidos.

De posse desses resultados, optou-se por testar a capacidade da fração purificada de ativar fator $X$ e $\mathrm{II}$, usando substratos sintéticos. Os resultados apontaram para uma ativação direta do fator $X$, uma vez que não houve ativação do fator II, atividade que também não foi detectada no veneno total. A mesma se mostrou um potente ativador da agregação de forma direta, uma vez que os ensaios de agregação plaquetária foram realizados com plaquetas lavadas, logo na ausência de fatores séricos. Quando os ensaios de agregação foram realizados na presença de alguns inibidores observou-se que nem a atividade metalo proteinase, nem a serino proteinase, tampouco um domínio lectina estavam envolvidos no processo, uma vez que EDTA, benzamidina e D-galactose não inibiram a atividade da proteína.

No presente trabalho isolamos a Delta toxina do veneno de $C$. $d$. terrificus. A mesma se comportou como previsto por Vital Brazil em 1980, eluindo na posição por ele aventada, sendo uma proteína ativadora de Fator $X$ que ativa agregação plaquetária mesmo em concentrações muito baixas e de massa molecular de $40 \mathrm{kDa}$ levando nos a crer se tratar de um homotrímero cujos componentes são unidos por ligaçōes fracas. 


\title{
ISOLATION AND CHARACTERIZATION OF DELTA TOXIN FROM THE VENOM OF Crotalus durissus terrificus
}

\author{
Lucélia de Almeida Campos
}

\begin{abstract}
The Crotalus durissus terrificus venom has been so far described as being of low complexity, with four major components described: convulxin, gyroxin, crotoxin and crotamine. In recent studies, other components of this venom were characterized as, for example, an analgesic factor. In 1980, Vital Brazil predicted the existence of a toxin which could be involved in platelet aggregation, and named it delta toxin. However, this toxin has never been isolated or characterized. The aim of the present work was to purify and characterize this toxin.

After FPLC size exclusion chromatography followed by reverse phase HPLC, an homogeneous fraction was obtained, with a molecular weight of 14,074.92 $\mathrm{Da}$. When analyzed by SDS-PAGE, this toxin presented an anomalous behavior, with a molecular weight of $14 \mathrm{kDa}$, while in $2 \mathrm{D}$ gels, spots around $40 \mathrm{kDa}$ and with an isoelectrical point between 4 and 5 were observed suggesting isoforms with glicosilation microheterogeneity. After trypsin digestion, the fragments were submitted to the swissprot databank showing high homology ( $43 \%$ coverage, 15 matching peptides) with trocarin, a prothrombin activator from Tropidechis carinatus. These data were further confirmed by aminoacid analysis.

The toxin was tested for its ability to activate factor II and X using synthetic substrates. Our data indicate a direct activation of factor $X$. The same toxin also behaved as a potent direct platelet aggregation activator on washed platelets. Assays with specific inhibitors indicate that neither metalloproteinase, nor serinoproteinase or $t$ lectin domains are involved in the aggregating activity, since EDTA, benzamidin and D-galactose did not inhibit the toxin.

In the presentent work, we were able to identify, purify and characterize a new toxin from the brazilian rattlesnake. It behaved as predicted by Vital-Brazil and displayed direct factor $X$ activating properties, also inducing platelet aggregation, even at low concentrations. Our data also indicate that it is probably a homotrimer with the subunities linked by hydrophobic and/or electrostatic interactions.
\end{abstract}




\section{SUMÁRIO}

1. INTRODUÇÃO

1.1. Hemostasia

2. OBJETIVOS

3. MATERIAIS E MÉTODOS 12

3.1. Varredura de tampões 12

3.2. Purificação do veneno crotálico (FPLC) - Exclusão Molecular 12

3.3. Cromatografia de Fase Reversa (HPLC) 13

3.4. Eletroforese em Gel de Poliacrilamida (SDS-Page) 14

3.5. Eletroforese Bidimencional 15

3.6. Seleção e Digestão dos "Spots"

3.7. MALDI-ToF 18

3.8. Peptide Mass Fingerprint por MALDI-ToF 19

3.9. Análise de Aminoácidos 20

3.10. Agregação Plaquetária 20

3.10.1. Obtenção do Plasma rico em Plaqueta 20

3.10.2. Plaquetas Lavadas 21

3.10.3. Inibidores de serino, metalo proteinases e lectina 22

3.11. Ativador de Fator X 22

3.12. Ativador de Fator II 22

3.13. Western Blotting 23

4. RESULTADOS 25

4.1. Varredura de tampões 25

4.2. Purificação do veneno crotálico (FPLC) - Exclusão Molecular 27

4.3. Cromatografia de Fase Reversa (HPLC) 27

4.4. Eletroforese em Gel de Poliacrilamida (SDS-Page) 30

4.5. Eletroforese Bidimencional 31

4.6. Seleção dos "Spots" e Peptide Mass Fingerprint por MALDI-ToF 32

4.7. MALDI-ToF 33

4.8. Análise de Aminoácidos 36

4.9. Agregação Plaquetária 37

4.9.1. Inibidore rino, metalo proteinases e lectina 39

4.10. Ative ...

4.11. Ativacor oe: .urll 42

4.12 ran D!otting 43

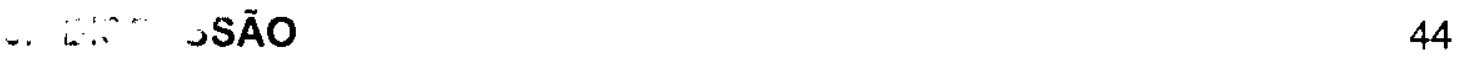

- JONCLUSÕES 49

7. REFERÊNCIAS BIBLIOGRÁFICAS 50 


\section{LISTA DE ABREVIATURAS}

$\begin{array}{ll}\text { CK } & \text { Creatinoquinase } \\ \text { kDa } & \text { quilodaltons } \\ \text { mg } & \text { miligramas } \\ \text { FPLC } & \text { Fast Protein Liquid Chromatograph } \\ \text { HPLC } & \text { High Performance Liquid Chromatograph } \\ \text { nm } & \text { nanômetros } \\ \text { TFA } & \text { Ácido trifluoro acético } \\ \text { SDS } & \text { Duodecil sulfato de sódio } \\ \text { SDS-PAGE } & \text { Eletroforese em gel de poliacrilamida com SDS } \\ \text { pl } & \text { Ponto isoelétrico } \\ \text { DTT } & \text { Ditiotreitol } \\ \text { V } & \text { Volts } \\ \text { Tris } & \text { Tris (hidroximetil)-aminometano } \\ \text { A } & \text { Amperes } \\ \text { MALDI-ToF } & \text { Matrix-assisted laser desorption ionization - time of flight } \\ \text { PMF } & \text { Peptide Mass Fingerprint } \\ \text { HCL } & \text { Ácido Clorídrico } \\ \text { g } & \text { Força centrifuga relativa } \\ \text { PL } & \text { Plaqueta Lavada } \\ \text { ADP } & \text { Adenosina difosfato } \\ \text { PBS } & \text { Tampão Fosfato Salina } \\ \text { EDTA } & \text { Ácido etilenodiamino tetracético } \\ \text { PMSF } & \text { Fenil metilsulfonil fluoreto } \\ \text { DAB } & \text { 3,3' Diaminobenzidina } \\ \text { 2D } & \text { Bidimensional } \\ \text { HEPES } & \text { Ácido 2-[4-(2-hidroxietil)-1-piperazinil]etanosulfônico } \\ \text { CHAPS } & \text { 3-3[(3-cholamidopropyl)dimethyl-ammonio]-1-propanesulfonate } \\ & \end{array}$




\section{INTRODUÇÃO}

Os venenos ofídicos são provavelmente os fluídos secretórios de vertebrados mais concentrados de que se têm noticias (Stocker, 1990) e são compostos por proteinas e peptideos que representam acima de $90 \%$ do peso seco. Estas biomoléculas são as responsáveis pelas atividades tóxicas e biológicas das peçonhas de serpentes.

Já foram descritas inúmeras toxinas e enzimas com um vastíssimo espectro de atividades (Theakston \& Kamiguti, 2002). Entre elas podemos citar enzimas que atuam em diversos pontos da cascata da coagulação (Monteiro \& Zingali, 2002, Rucavado et al. 2001), toxinas que atuam em canais iônicos, proteases que interferem com a integridade do endotélio (Zamuner \& Teixeira, 2002), fosfolipases (Lizano et al., 2001), L-amino ácido dehidrogenases (Tempone et al., 2001).

Os venenos, assim como outras substâncias naturais têm despertado um grande interesse pela diversidade de principios ativos que encerram e pelo potencial que estes compostos apresentam de levar à sintese de novas drogas ou ao desenvolvimento de novas ferramentas nas áreas de farmacologia, hemostasia, neurofisiologia e outras.

O veneno da serpente Crotalus durissus terrificus tem sido descrito como de pouca complexidade. Essa serpente encontra-se distribuida no Brasil nas zonas altas e secas, sul oriental e meridional, desde o Rio Grande do Sul até Minas Gerais. Sua denominação popular é cascavel ou boiquira. O veneno apresenta efeitos importantes sobre os músculos esqueléticos, sistema nervoso, rins e sangue. Outros órgãos como o fígado também pode ser acometido 
(Barravieira, 1994). O veneno crotálico também induz rabdomiólise generalizada, mialgia, aumento dos niveis de creatinoquinase (CK) acompanhado de mioglobinúria e dor por todo o corpo (Sano-Martins et al., 2001). A letalidade dos acidentes ofídicos envolvendo serpentes do gênero Crotalus tem o maior índice observado, com 1,87\% de óbito (FUNASA/MS, 2001). A soroterapia è o tratamento mais adequado para os casos de acidentes ofídicos, o soro anticrotálico deve ser administrado intravenosamente e a dose varia de acordo com a gravidade do caso. A hidratação adequada é fundamental para a prevenção da insuficiência renal aguda (FUNASA/MS).

Foram isoladas e caracterizadas 4 principais toxinas deste veneno: convulxina, giroxina, crotoxina e crotamina (Takeda et al., 1985).

A convulxina foi isolada em 1970 por Prado-Franscesci, é uma glicoproteína neurotóxica de alto peso molecular, cerca de $70 \mathrm{kDa}$ provoca distúrbios no sistema nervoso autônomo, efeitos como convulsões tônicoclônicas, perda de equilibrio, alterações circulatórias e respiratórias, ativação e agregação plaquetária, na ausência de fibrinogênio. Esta proteina foi descoberta após observarem que efeitos como alterações respiratórias e circulatórias não poderiam ser atribuidos as toxinas já isoladas na época como a crotoxina e a crotamina (Vital Brazil, Prado-Franceschi \& Ezequiel Waisbich, 1967; PradoFranceschi \& Vital Brazil, 1981,Vargaftig, 1983).

Outro grupo de componentes do veneno é o das enzimas, entre as quais, pela importância clínica, destaca-se uma enzima tipo trombina demonstrada por Nahas e isolada por Raw et al. em 1986, provavelmente envolvida nos distúrbios 
da coagulação sanguínea observada em cerca de $40 \%$ dos pacientes (Azevedo Marques et al., 1992).

As alterações observadas nos fatores de coagulação estão relacionadas à enzima tipo trombina, um componente das frações do veneno que tem a capacidade de transformar in vitro, fibrinogênio em fibrina, isto resulta em um consumo de fatores de coagulação e, conseqüentemente, na incoagulabilidade sanguinea (Barravieira, 1994).

A giroxina possui peso molecular de $33 \mathrm{kDa}$ e provoca sindrome convulsiva, caracterizada por movimentos circulatórios ao longo do seu eixo longitudinal do corpo lembrando o rolar de um barril (Silva 2004), característico em camundongos. A giroxina também apresenta atividade coagulante do fibrinogênio no plasma, exercendo assim uma atividade do tipo trombina (Barrio, 1961; Alexander et al., 1988).

A crotoxina foi primeiramente descrita como a proteina majoritária do veneno, possui $23 \mathrm{kDa}$, representa $60 \%$ do veneno total de Crotalus durissus terrificus apresenta alta toxicidade (Slotta \& Fraenkel-Conrat. 1938). É uma neurotoxina pré-sinaptica que atua nas terminações nervosas motoras inibindo a liberação de acetilcolina pelos impulsos nervosos, sendo este o principal fator responsável pelo bloqueio neuromuscular e portanto pelas paralisias motoras e respiratórias observadas nos animais (Vital Brazil \& Bárbara Excell, 1970; Azevedo Marques et al, 1992). Esta neurotoxina é composta por duas subunidades ligadas não covalentemente. A sub-unidade ácida é enzimaticamente inativa e não possui toxicidade, é também conhecida como crotapotina e potencializa a ação da fosfolipase (sub-unidade básica) (Bon et al.. 1986). 
A crotamina é um polipeptídeo básico de $4.8 \mathrm{kDa}$ que atua na membrana das fibras musculares alterando sua permeabilidade ao sódio, produzindo espasmos musculares (Moura Gonçalves e Laura Gouvêa, 1950; Azevedo Marques et al., 1992).

Apesar da extensa literatura a respeito deste veneno e de seus componentes, poucos trabalhos têm focado o isolamento de eventuais toxinas ainda não descritas, levando a crer que este veneno encerra unicamente os componentes acima descritos. No entanto, evidências apontam para a presença de outros constituintes. Entre eles, podemos citar a hialuronidase, que vem sendo isolada por um grupo de Ribeirão Preto (Bomfim, comunicação pessoal). Uma fração de baixo peso molecular e com potente ação analgésica está parciaimente isolada

Vital-Brazil (1980) sugeriu a existência de uma toxina que eluiria entre a convulxina e a giroxina quando o veneno é fracionado por cromatografia de exclusão molecular e que estaria envolvida na agregação plaquetária, alteração da permeabilidade vascular e causar grande hemoconcentração. Esta proteína foi então denominada por ele de delta toxina (Vital Brazil, 1980). Apesar de citada na literatura, esta toxina nunca foi isolada, tampouco caracterizada.

A maioria dos trabalhos que envolvem fracionamento do veneno de C.d. terrificus utiliza resinas cromatográficas de baixa resolução, resultando em 4 picos principais, que representam as toxinas acima descritas. No trabalho de Nascimento (1991), a purificação do veneno crotálico em resina Sephadex G75 resultou em quatro frações como mostra a Figura 1. 


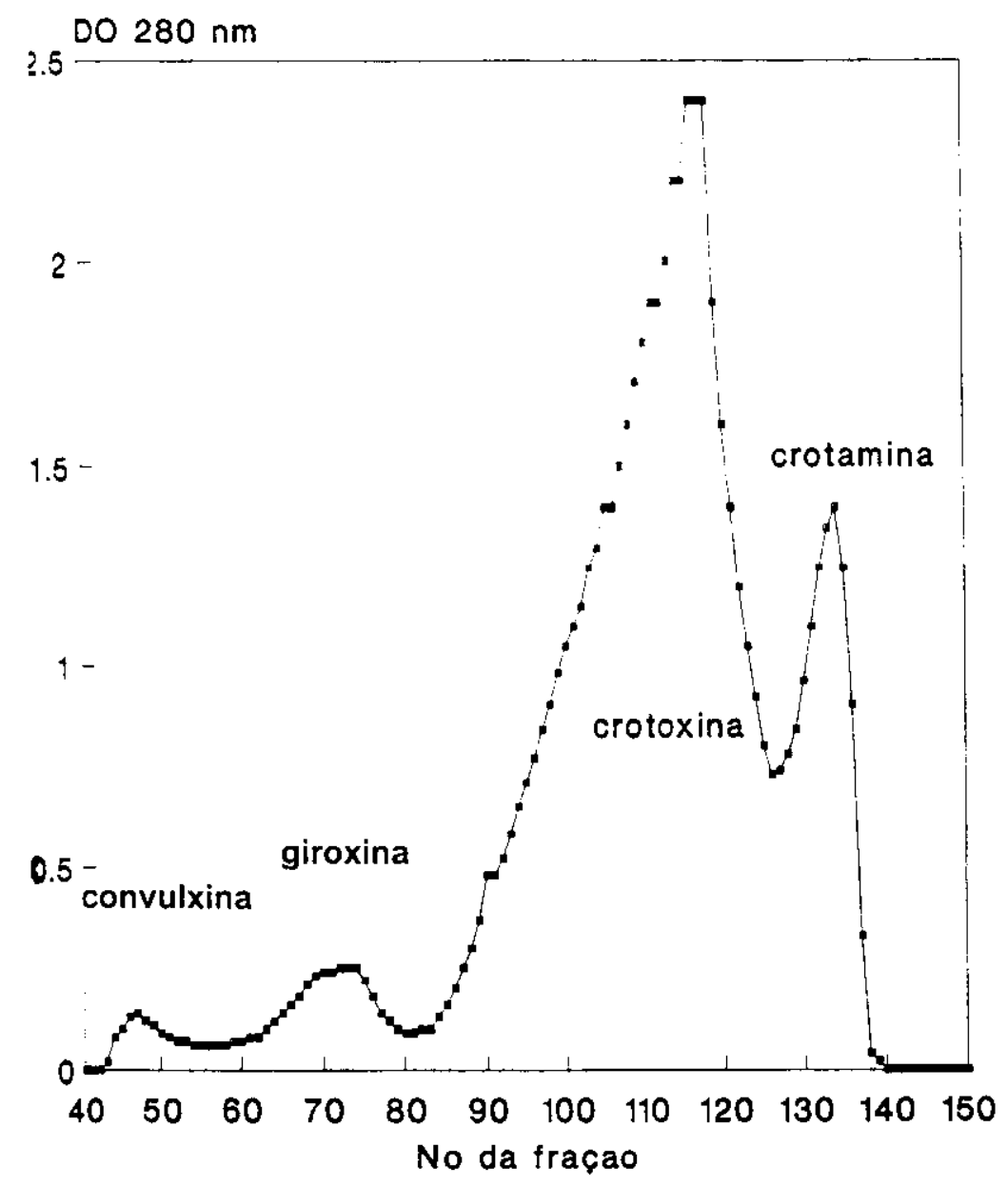

Figura. 1 - Perfil de eluição de veneno crotálico em resina Sephadex G75. Fluxo $12 \mathrm{~mL} /$ hora

Em experimentos recentes, que utilizaram resinas mais modernas (maior resolução). foi possivel verificar um pico adicional na mesma posição descrita por Vital Brazil. Na Figura 2 está representado o perfil cromatográfico do veneno de C.d. terrificus, usando uma resina Superdex 75 (Casare, 2003). 


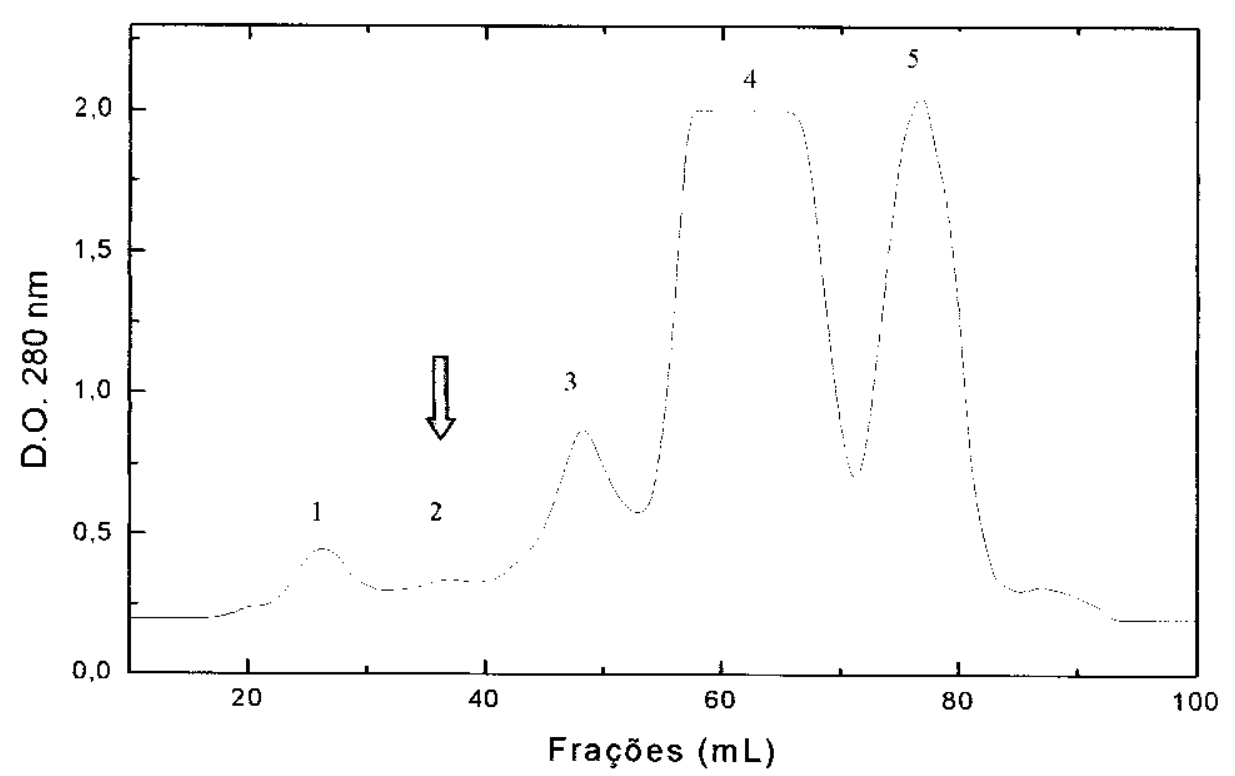

Figura.2 - Perfil de eluição de veneno crotálico em resina Superdex 75 Fluxo: $30 \mathrm{ml} / \mathrm{hora}$.

Análises preliminares desta fração, por eletroforese em gel de poliacrilamida, indicam a existência de bandas cujo peso molecular não é compativel com aqueles previamente descritos, sugerindo que nesta fração se encontram biomoléculas ainda näo relatadas no veneno crotálico. Além do interesse acadêmico, a análise destes componentes também pode ser relevante do ponto de vista clínico, uma vez que, estas toxinas podem ter papel importante na patologia do acidente crotálico. 


\subsection{Hemostasia}

A hemostasia é um processo pelo qual o organismo torna-se capaz de estancar um sangramento e manter o sangue fluido dentro do compartimento vascular.

A coagulação consiste em uma série de mecanismos bioquimicos com a finalidade de consolidar o tamponamento através da deposição de redes de fibrina. Esse sistema envolve os vasos sanguineos, as plaquetas, os fatores prócoagulantes plasmáticos e agentes fibrinolíticos. Existe ainda sistema calicreínacinina e os inibidores das serino proteases (fatores coagulantes) e cada fator plasmático têm uma propriedade especifica (Oliveira, 1998).

O coágulo sanguíneo se forma de acordo com as três etapas citadas: Primeiro uma substância, ou um complexo de substâncias, denominada ativador de protrombina é formado em resposta à ruptura de um vaso ou lesão. Segundo, o ativador da protrombina catalisa a conversão de protrombina em trombina. Terceiro, a trombina atua como uma enzima para converter o fibrinogênio (solúvel) em fibrina (insolúvel) aos quais aderem plaquetas, eritrócitos e plasma. formando o coágulo (Guyton, 1999).

A cascata de coagulação pode ser desencadeada após uma lesão por dois processos:

Via Extrinseca:

Principal via de inicialização da coagulação sanguínea que envolve componentes do sangue e elementos vasculares. $O$ processo se inicia quando 0 sangue entra em contato com um tecido extravascular traumatizado, e este libera dois fatores que desencadeiam o processo de coagulaçāo: o fator tecidual que é 
uma enzima proteolítica e os fosfolipidios teciduais, presentes nas membranas celulares.

O fator tecidual combina-se com o fator VII da coagulação e este complexo na presença de fosfolipidios teciduais atuam sobre o fator $\mathrm{X}$ formando o FXa. Este combina-se imediatamente com os fosfolipidios e também com o fator $\mathrm{V}$, formando o complexo denominado ativador da protrombina. Este converte a protrombina em trombina, dando continuidade ao processo de coagulação.

Via Intrínseca:

Após o trauma. o segundo mecanismo inicia-se quando dois fatores da coagulação são alterados, o fator XII e as plaquetas. Quando o FXII entra em contato com o colágeno, ele se converte em uma enzima proteolítica denominado FXII ativado. Simultaneamente o trauma lesa as plaquetas que liberam fator plaquetário III.

O Fator Xlla ativa o Fator XI transformando em FXla, que por sua vez reage enzimaticamente com o Fator IX passando para a forma FIXa.

? FIXa em ação conjunta com o Fator VIII e fosfolipidios plaquetários ativam o Fator X. Agora com o FXa em combinação com o FV formarão um complexo ativador de protrombina (Guyton, 1999).

No final do processo de coagulação ambas vias são processadas e resultam no ponto comum de formação de FXa, o qual é responsável pela geração de trombina. Assim a trombina converte fibrinogênio em monômeros de fibrina que sofrem a ação do FXIII através de uma reação de trans-glutaminação formando polímeros de fibrina. Por outro lado, o plasminogênio, sob ação de 
ativadores de plasminogênio (UPA ou tPA) é transformado em plasmina a qual degrada fibrina em vários fragmentos (Rissi-Silva, 2004).

Atualmente são conhecidos mais de 100 diferentes tipos de venenos de serpentes que afetam o sistema hemostático por vários mecanismos (Marckłand, 1998)

O envenenamento causado por $C$.durissus é freqüentemente associado a disfunção hemostática, provavelmente pela ação de enzimas trombina-simile. Os distúrbios de coagulação tem sido descritos em cerca de $50 \%$ dos pacientes picados por C.durissus (Sano-Martins et al., 2001)

A maioria das serpentes da familia Crotalidae apresenta enzimas responsáveis pelos efeitos hemostáticos dos envenenamentos. O mecanismo pelo qual estas proteinas podem atuar é variado (Stocker et al., 1982). Dentre os componentes dos venenos ofidicos, vários são os que afetam o mecanismo hemostático, incluindo a coagulação, a fibrinólise, a função plaquetária e a integridade vascular.

A atividade pró-coagulante dos venenos tem como alvo principalmente os últimos fatores da cascata de coagulação, como por exemplo o fibrinogênio, a protrombina e o Fator X (Joseph et al., 1999).

Enzimas que atuam sobre o fibrinogênio para formar fibrina, denominadas trombina-símile, foram isoladas de venenos de serpentes. Algumas destas enzimas clivam an'untamente, as cadeias $\mathrm{Aa}$ e $\mathrm{Bb}$ do fibrinogênio, liberando os fibrinupepriceos A e B. Outras clivam apenas a cadeia Aa, liberando o fibrinopepiueo: jlocker et al., 1982). 
As serino proteases dos venenos ofídicos estão entre as enzimas que afetam o sistema hemostático. Em geral essas proteínas afetam as vias da cascata da coagulação, ativando especificamente componentes do sangue envolvidos na coagulação, levando à fibrinólise e agregação plaquetária ou degradação proteolitica (Serrano \& Maroun, 2005).

$O$ isolamento de novas toxinas que modulam a hemostasia, é de importância fundamental nos estudos clinicos e na pesquisa cientifica. no sentido de fornecer novas ferramentas para o estudo dos mecanismos envolvidos na cascata da coagulação. 


\section{OBJETIVO}

presente trabalho visa determinar as condições ideais para isolar a delta toxina do veneno total de Crotalus durissus terrificus e caracterizar a mesma do ponto de vista bioquímico, assim como identificar os seus possiveis alvos fisiológicos. 


\section{MATERIAIS E MÉTODOS}

O veneno de Crotalus durissis terrificus foi gentilmente cedido pelo Centro de Estudos de Venenos e Animais Peçonhentos CEVAP-Botucatu.

\subsection{Varredura de tampões}

Em uma coluna Superdex 75 de exclusão molecular, testaram-se diferentes tampões para determinar aquele que resultaria em uma melhor resolução das frações purificadas.

Para tal, $25 \mathrm{mg}$ de veneno crotálico foram dissolvidos em 1,2 $\mathrm{mL}$ do tampão apropriado, centrifugados e o sobrenadante foi injetado em uma coluna Superdex $75(1,6 \times 70 \mathrm{~cm})$, acoplada a um sistema FPLC, previamente ambientada no mesmo tampão. A cromatografia foi realizada no modo analítico sem a coleta do eluato.

O processo foi realizado utilizando-se os tampões formiato de amônio $(0,1 \mathrm{M} \mathrm{pH} 3.0)$, acetato de sódio $(0,1 \mathrm{M} \mathrm{pH} 5.0)$ ou citrato de sódio $(0,1 \mathrm{M} \mathrm{pH} 5.0)$.

\subsection{Purificação do veneno crotálico (FPLC) - Exclusão Molecular}

A cromatografia por exclusão molecular baseia-se na separação de proteínas de acordo com seus pesos moleculares. É a técnica ideal para amostras com pouco volume. As amostras são eluídas na presença de um 
simples tampão sem gradiente (Fischer, 1990; Amersham Pharmacia biotech, 1999).

Sucessivas purificações foram realizadas para a obtenção da toxina de interesse.

Aliquotas de cerca de $100 \mathrm{mg}$ de veneno foram dissolvidas em $1,2 \mathrm{~mL}$ de

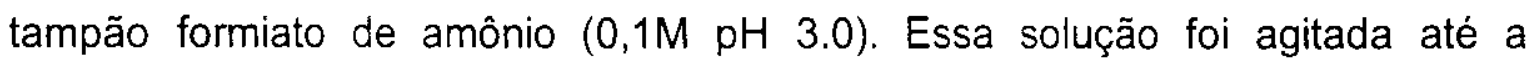
solubilização total do veneno e posteriormente centrifugada a $11.326 \mathrm{~g} \mathrm{em}$ uma microcentrifuga. O sobrenadante foi injetado em uma coluna Superdex $75(1,6 \times$ $70 \mathrm{~cm}$ ) de exclusão molecular acoplada a um sistema FPLC (Pharmacia), previamente ambientada com o tampão formiato de amônio. A absorvância do eluato foi medida a $280 \mathrm{~nm}$. Foram coletadas frações de $1 \mathrm{~mL}$ por tubo.

Após as purificações a fração de interesse foi congelada e liofilizada.

\subsection{Cromatografia de fase reversa (HPLC)}

A cromatografia de fase reversa baseia-se na separação de proteínas e peptídeos de acordo com a interação reversivel da amostra com a superfície hidrofóbica da coluna cromatográfica. A ligação é normalmente muito forte e requer o uso de um solvente orgânico para a eluição da proteina (Amersham Pharmacia biotec, 1999)

O segundo pico coletado depois da cromatografia de exclusão molecular, foi liofilizado e ressuscenuido em $1 \mathrm{~mL}$ de TFA (Ácido trifluoro acético) 0,1\%. A seguir este maeri u injetado ( $400 \mu \mathrm{L} /$ corrida) em uma coluna de fase reversa Vydak $+r e$ o $\times 200 \mathrm{~mm}$, precedida de uma pré-coluna do mesmo fabricante 
conectada a um cromatográfo Shimadzu. Após uma lavagem com $5 \mathrm{~mL}$ de solução A (TFA $0,1 \%$ ), para eluição da fração não adsorvida, iniciou-se um gradiente de 0 a $100 \%$ de $B$ (acetonitrila mais $0,05 \%$ de TFA) em 20 minutos. Findo o gradiente, manteve-se esta condição por mais $5 \mathrm{~mL}$, retornando-se então para a condição inicial. O fluxo utilizado foi de $1 \mathrm{~mL} /$ minuto e a absorvância do eluato foi monitorada a $220 \mathrm{~nm}$. Com o intuito de identificar o pico de interesse, foram também injetadas aliquotas dos picos 1 e 3 , permitindo assim eliminar os picos correspondendo aos contaminantes. Foi também realizada uma corrida falsa, utilizando apenas tampão, visando identificar possiveis ruidos na linha base.

\subsection{Eletroforese em gel de Poliacrilamida (SDS-PAGE)}

A eletroforese é uma técnica laboratorial usada para separação de macromoléculas de acordo com sua carga ou tamanho. Essa separação ocorre com a migração da proteina através de uma matriz de gel sob a influência de um campo elétrico. (Baptista, 2004).

Dissolveu-se $1 \mathrm{mg}$ de veneno de Crotalus durissus terrificus em $500 \mu \mathrm{L}$ de solução salina chegando a uma concentração final de $2 \mathrm{mg} / \mathrm{mL}$. Amostras com veneno total foram preparadas com tampão de amostra com e sem agente redutor.

Um miligrama de delta-toxina liofilizada após fracionamento em FPLC foi diluido em $500 \mu \mathrm{L}$ de água destilada. Amostras com a delta toxina semi-pura 
foram preparadas com tampão de amostra em condições recutoras e não redutoras. O mesmo foi feito com o pico correspondente a Delta toxina após a purificação em sistema HPLC.

As amostras foram aquecidas a $95^{\circ} \mathrm{C}$ por 5 minutos, e posteriormente aplicadas em um gel de poliacrilamida a $12 \%$, utilizando o sistema de tampões descrito por Laemmli, (1970) . No gel aplicou-se também um padrão de peso molecular conhecido. A voltagem foi fixada em 90 volts.

Finda a eletroforese, o gel foi corado com Coomassie blue 250-R, por 1 hora, sendo posteriormente descorado com solução contendo $30 \%$ de etanol e $10 \%$ de Ácido Acético.

\subsection{Eletroforese Bidimensional}

A Eletroforese 2D é um método usado para análise de complexos protéicos extraídos de amostras biológicas. Essa técnica separa proteinas de acordo com duas propriedades independentes em dois passos diferentes: o primeiro passo, a focalização isoelétrica, separa proteínas de acordo com o ponto isoelétrico $(\mathrm{pl}) ; \quad$ O segundo passo, o SDS PAGE, eletroforese em gel de poliacrilamida, separa então as bandas da primeira dimensão de acordo com seu peso molecular.

\section{Preparo da amostra:}

Aproximadamente $1 \mathrm{mg}$ de amostra liofilizada resultante do pico $2 \mathrm{da}$ exclusão molecular foi solubilizada em solução de rehidratação contendo uréia 
8M. CHAPS $2 \%$, tampão com carreadores de anfólitos $0.5 \%$ e azul de bromofenol. Instantes antes da rehidratação da tira, adicionou-se 0,3 $\mu \mathrm{L}$ de IPG Buffer (Amersham Biosciences) e 0,7 $\mu \mathrm{L}$ de DTT (Ditiotreitol), obtendo-se um volume total de $350 \mu \mathrm{L}$. Aplicou-se a solução sob a tira de $18 \mathrm{~cm} \mathrm{pH} \mathrm{4-7} \mathrm{e} \mathrm{a}$ rehidratação foi realizada no apareho IPGphor (Amersham Biosciences) por 12 horas, sob voltagem de $30 \mathrm{~V}$.

Após a hidratação, iniciou-se a focalização isoelétrica. Inicialmente, a tira foi submetida a uma diferença de potencial de $500 \mathrm{~V}$ por uma hora. A seguir, a voitagem foi aumentada para $1000 \mathrm{~V}$ por uma hora. Na última etapa, a voltagem foi elevada para $8000 \mathrm{~V}$ até atingir um total de $32000 \mathrm{~V} / \mathrm{hora}$.

Finda a focalização as tiras foram colocadas em $15 \mathrm{~mL}$ de solução de equilíbrio contendo $50 \mathrm{mM}$ de Tris- $\mathrm{HCl}, \mathrm{pH} 8,8,6 \mathrm{M}$ uréia, 30\% Glicerol, 2\% SDS (dodecil sulfato de sódio), azul de bromofenol e $65 \mathrm{mM}$ de DTT (Ditiotreitol). Após 15 minutos sob agitação constante, a solução acima foi substituida por uma solução similar, substituindo o DTT por iodoacetamida $135 \mathrm{mM}$ para promover a carboximetilação dos grupamentos tiol.

Na segunda dimensão, a tira foi posicionada sobre o gel de poliacrilamida (14\%) $20 \times 25 \mathrm{~cm}$ e em um dos lados foi colocado um marcador de peso molecular. Adicionou-se uma solução seladora contendo $0,5 \%$ de agarose em Tris 25 $\mathrm{mM} / \mathrm{Glicina} 200 \mathrm{mM}$ contendo $0,01 \%$ de SDS. A eletroforese foi efetuada em uma cuba Hoefer ${ }^{\circledR}$ DALT (Amersham Biosciences) aplicando-se uma corrente de $30 \mathrm{~mA}$ até que a frente de azul de bromofenol alcançasse a extremidade inferior do gel. 
Após a corrida o gel foi fixado por duas horas em uma solução contendo $50 \%$ de metanol e $10 \%$ de ácido acético. A coloração foi feita "over night" em Coomassie Blue (Serrano, 2004).

\subsection{Seleção e digestão dos "Spots"}

Os "spots" foram analisados de acordo com o ponto isoelétrico e a massa molecular. Estes então foram recortados e colocados em "eppendorfs" individualmente identificados. O protocolo de digestão e extração abaixo baseouse naquele descrito por Westermeier e Naven (2002).

Adicionou-se $100 \mu \mathrm{L}$ de solução $75 \mathrm{mM}$ de bicarbonato de amônio em etanol $40 \%$ para a remoção do corante, agitando-se a mistura e incubando-se por 10 minutos. Esse procedimento foi repetido até a descoloração total do gel.

As proteínas contidas no gel foram então reduzidas pela adição de DTT $5 \mathrm{mM}$ em bicarbonato de amônio $25 \mathrm{mM}$, incubando-se os tubos por 30 minutos a $60^{\circ} \mathrm{C}$.

Após a remoção da solução redutora, foram adicionados $10 \mu \mathrm{L}$ de iodacetamida $55 \mathrm{mM}$ em bicarbonato de amônio $25 \mathrm{mM}$ e esta mistura foi incubada no em câmara escura por 30 minutos à temperatura ambiente. Após a remoção do sobrenadante, os "spots" foram lavados com bicarbonato $25 \mathrm{mM}$ sequir atrila. O gel foi então triturado e desidratado por sucessivas lavagens com acetonitrila ( $3 \times 25 \mu \mathrm{L}, 10$ minutos cada) e seco em "speed vac".

A rehidratação foi feita com a aplicação de $2 \mu \mathrm{L}$ de tripsina (grau seqüenciamento) a $40 \mathrm{ng} / \mu \mathrm{L}$ e quantidade suficiente de tampão de bicarbonato de 
amônio $50 \mathrm{mM}$ para cobrir o gel por completo, mantendo-se o mesmo resfriado por 45 minutos. O sobrenadante foi retirado e adicionou-se a solução tampão (sem a enzima) até cobrir os pedaços de gel, mantendo o mesmo a $30^{\circ} \mathrm{C}$ por 16 horas.

Para a extração dos peptídeos adicionou-se $20 \mu \mathrm{L}$ de bicarbonato de amônio $50 \mathrm{mM}$ e as amostras foram colocadas em banho de ultra-som por 10 minutos. Adicionou-se $20 \mu \mathrm{L}$ de acetonitrila/ 5\% TFA (1:1) e a amostra permaneceu em banho de ultra-som por mais 10 minutos. O sobrenadante foi transferido para outro tubo e o procedimento foi repetido por mais três vezes. Adicionou-se então $10 \mu \mathrm{L}$ de acetonitrila e os spots foram colocados mais uma vez em banho de ultra-som por 10 minutos. O sobrenadante foi retirado $\mathrm{e}$ adicionado aos sobrenadantes anteriores.

\subsection{MALDI-TOF}

Espectrometria de massa é a análise ou separação de partículas carregadas em fase gasosa, tais como átomos e moléculas ionizadas, baseados em uma relação carga/massa. Os ions produzidos ma fonte de ionização são separados em um analisador e seguem para o detector (Aebersold \& Mann, 2003; Lind et al, 2003).

Para a espectrometria de massa tipo MALDI-TOF, as análises foram realizadas com amostras pura e semi-pura de delta toxina, em um equipamento MALDI-ToF/Pro (Amersham). As amostras, em solução, foram misturadas na 
proporção 1:1 (v:v) com uma solução supersaturada de matriz para peptídeos (ácido cinâmico) ou matriz para proteinas (ácido sinápico): depositadas sobre a placa de amostragem $(0,4-0,8 \mu \mathrm{L})$ e deixadas secar no ambiente. Foi utilizado o modo automático de controle do equipamento e aquisição de dados.

\subsection{Peptide Mass fingerprint por MALDI-ToF}

Para o mapeamento peptídico, as proteínas são diferenciadas com base em seu padrão de fragmentação. A proteina é clivada na porção C-terminal dos aminoácidos básicos (ARG e LYS) após passar por uma digestão com tripsina (Ricci-Silva, 2004).

Para PMF (peptide mass fingerprinting) os ions detectados foram analisados pelo banco de dados local (pertencente ao software de controle e aquisição de dados) e/ou pelos bancos de dados públicos disponíveis na Internet, principalmente pelo MASCOT (Lin D. et al. 2003).

\subsection{Análise de Aminoácidos}

Técnica utilizada para determinação quantitativa dos aminoácidos que compõem uma dada proteína. Baseia-se na hidrólise ácida da ligação peptídica que une os aminoácidos e a quantificação destes em sistema cromatográfico automatizado. 
A composição de aminoácidos foi determinada através da hidrólise ácida e derivatização pós coluna, com ninidrina. Estes foram analisados em um analisador automático BioChrom 20 Plus (Amersham Biosciences), provido de válvulas injetoras de amostras. O sistema foi periodicamente calibrado com uma mistura padrão de aminoácidos, obtendo-se um valor para o tempo de eluição de cada aminoácido e um fator de correção entre a área de cada pico e a concentração de aminoácidos na amostra.

A amostra de proteína (+/- $1 \mathrm{mg}$ ) foi hidrolisada em $1 \mathrm{~mL}$ de $\mathrm{HCl} 6 \mathrm{M}$, na presença de $0,08 \mathrm{~mL}$ de fenol a $5 \%$ em água $(\mathrm{v} / \mathrm{v})$, a $110^{\circ} \mathrm{C}$ por 72 horas em atmosfera de nitrogênio. Após a hidrólise, o material foi concentrado a vácuo, ressuspendido em citrato de sódio $0,2 \mathrm{M}, \mathrm{pH} \mathrm{2,2}$ e filtrado em membrana Millipore, antes de ser injetado no aparelho (Poletti, 2006).

\subsection{Agregação Plaquetária}

\subsubsection{Plasma rico em plaquetas}

O sanque venoso humano de doadores saudáveis $(9 \mathrm{~mL})$ foi coletado em twbo wasisco contendo $1 \mathrm{~mL}$ de citrato de sódio $3,8 \%$. O sangue foi centrifugado durante 25 minutos a $129 \mathrm{~g}$ (centrifuga 5810R eppendorf) em temperatura ambiente para a obtenção do plasma rico em plaquetas (PRP).

\subsubsection{Plaquetas lavadas}

Para a obtenção de plaquetas lavadas (PL), EDTA $2 \%$ foi adicionado ao PRP na proporção 1:20 e esta mistura centrifugada por 15 minutos a $1258 \mathrm{~g}$. 
Após ser desprezado o sobrenadante, o "pellet" plaquetário foi dissolvido em 10 $\mathrm{mL}$ de tampão de lavagem ( $818 \mathrm{mg} \mathrm{NaCl}, 84 \mathrm{mg} \mathrm{NaHCO} 3,19 \mathrm{mg} \mathrm{KCl}, 13 \mathrm{mg}$ $\mathrm{Na}_{2} \mathrm{HPO}_{3}, 20 \mathrm{mg} \mathrm{MgCl}, 646 \mathrm{mg} \mathrm{Na}$ CitratO, $10 \mathrm{mg}$ glicose. $350 \mathrm{mg} \mathrm{BSA}$, dissolvidos em $100 \mathrm{~mL}$ de $\mathrm{H} 2 \mathrm{O}, \mathrm{pH}$ ajustado para $6,5 \mathrm{com} \mathrm{HCl}$ ) e a mistura centrifugada por 15 minutos a $1258 \mathrm{~g}$. Após repetir a etapa anterior, novamente o sobrenadante foi desprezado e o "pellet" redissolvido em $2 \mathrm{~mL}$ de solução Tyrode (783 mg NaCl, $100 \mathrm{mg} \mathrm{NaHCO} 3,22 \mathrm{mg} \mathrm{KCl}, 9 \mathrm{mg} \mathrm{Na} 2 \mathrm{HPO}_{4}, 20 \mathrm{mg} \mathrm{MgCl}, 14 \mathrm{mg}$ $\mathrm{CaCl}_{2}, 238 \mathrm{mg} \mathrm{HEPES} \mathrm{pH}$ ajustado para $7,4 \mathrm{com} \mathrm{HCl}$ ) contendo glicose $1 \%$. As plaquetas foram contadas em Serono-Baker 9020+AX System e ajustadas com solução Tyrode para atingir a concentração de $400 \times 10^{9} / \mathrm{L}$.

Os efeitos da proteína sobre a agregação plaquetária, foram estudados por meio da incubação das mesmas com $\mathrm{PL}$ (plaqueta lavada) por 5 minutos a $37^{\circ} \mathrm{C}$, sob agitação. A transmissão de luz foi monitorada com o auxílio de um agregômetro (CHRONO-LOG), calibrado para 100\% de transmitância com Tyrode e para $0 \%$ de transmitância com a solução de plaquetas lavadas (400 x 109/L).

O controle positivo foi feito com a adição de $10 \mu \mathrm{M}$ de colágeno após a incubação com PBS sobre a PL. Amostras de delta toxina foram testadas em várias concentrações, variando de $144 \mu \mathrm{g} / \mathrm{mL}$ até $0,9 \mu \mathrm{g} / \mathrm{mL}$ por ensaio.

3.10.3. Inibidores de serino protease, metalo protease e lectina.

Para o teste com inibidores de serino, metalo proteinases e lectinas as amostras de delta toxina (na concentração de $18 \mu \mathrm{g} / \mathrm{mL}$ ) foram incubadas com PMSF (Fenil metil sulfonil fluoreto) $5 \mathrm{mM}$ ou EDTA (ácido etilenodiamina tetraacético) $5 \mathrm{mM}$ e 0,2 mM, D-galactose $5 \mathrm{mM}$ e $16 \mathrm{mM}, 1,10$-fenantrolina $5 \mathrm{mM} \mathrm{e}$ 
$10 \mathrm{mM}$ e benzamidina $5 \mathrm{mM}$ e $25 \mathrm{mM}$, por 30 minutos a $37^{\circ} \mathrm{C}$. Após a incubação as amostras foram testadas em plaquetas lavadas e monitoradas pelo agregômetro (Aguilar, et al., 2001, Laing et.al., 2005).

\subsection{Ativador de fator $X$}

A ativação do fator $X$ foi medida por meio da atividade amidolítica de fator Xa formado, utilizando um espectrofotômetro Modelo Ultrospec III (Pharmacia LKB Biotech) (450nm) após a incubação de $10 \mu \mathrm{L}$ de amostra $(2 \mathrm{mg} / \mathrm{mL})$ ou controle a $37^{\circ} \mathrm{C}$ com $40 \mathrm{mM}$ de substrato cromogênico (F3301 Sigma) e $0.3 \mathrm{nM}$ de fator $\mathrm{X}$ bovino em tampão Tris- $\mathrm{HCl} 25 \mathrm{nM}, \mathrm{NaCl} 200 \mathrm{mM}, \mathrm{CaCl}_{2} 10 \mathrm{mM}, \mathrm{pH}$ 8.3. A leitura foi feita em diversos tempos (Hofmann e Bon, 1987).

\subsection{Ativador de Fator II}

A ativação do fator II foi medida por meio da atividade amidolítica de fator Ila formado, utilizando um espectrofotômetro (450nm) após a incubação de $10 \mu \mathrm{L}$ de amostra $(2 \mathrm{mg} / \mathrm{mL})$ ou controle a $37^{\circ} \mathrm{C}$ com $40 \mathrm{mM}$ de substrato cromogênico (F2238 Sigma) e 148nM de fator II em tampão Tris- $\mathrm{HCl} 25 \mathrm{nM}, \mathrm{NaCl} 200 \mathrm{mM}$, $\mathrm{CaCl}_{2} 10 \mathrm{mM}, \mathrm{pH} 8,3$. A leitura foi feita em diversos tempos (Silva et al. 2003). 


\subsection{Western Blotting}

Western blotting é um método para detectar a interação de proteinas com anticorpos. Essa técnica usa eletroforese em gel para separar as proteinas denaturadas por peso molecular. As proteínas são então transferidas do gel para uma membrana (tipicamente de nitrocelulose), onde são usados como sonda anticorpos específicos para a proteina. A reação antígeno-anticorpo pode ser detectada por um segundo anticorpo marcado, dirigido contra o primeiro anticorpo. A revelação é feita por técnicas imunoquímicas (Towbin et. al., 1979, De Paula, 1995).

Após a realização de uma eletroforese em gel de poliacrilamida a $12 \%$ com as amostras de veneno total e delta toxina pura em condições redutoras e não redutoras, as proteínas do gel foram transferidas para uma membrana de nitrocelulose em uma cuba de transferência de western blotting sob uma corrente elétrica fixada em $0,85 \mathrm{~mA} / \mathrm{cm}^{2}$. A transferência durou 1 hora e 30 minutos. A membrana de nitrocelulose foi então retirada da cuba e lavada por 1 hora com PBS+leite desnatado (3\%) sob leve agitação.

Após a lavagem, iniciou-se a incubação da membrana com a solução de

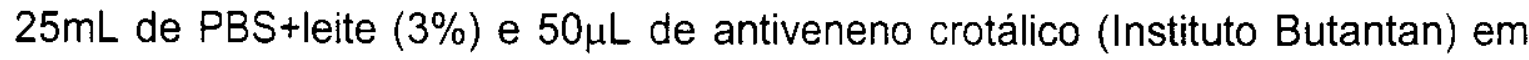
uma concentração final de 1:500. Essa solução foi colocada em um recipiente com a membrane - : permaneceram "overnight" sob leve agitação a $4^{\circ} \mathrm{C}$.

A memt ir retirada e lavada com PBS 3 vezes por 10 minutos. 
Uma segunda solução com $20 \mathrm{~mL}$ de PBS+leite (3\%) e $20 \mu \mathrm{L}$ de IgG de coetho anti IGg de cavalo conjugada com peroxidase ( $2^{\circ}$ Ac.) na proporção 1:1000 foi adicionada a membrana, que permaneceu sob agitação por 2 horas. A membrana foi lavada com PBS por 3 vezes e então adicionou-se a solução de revelação contendo o cromogênio DAB (3,3' Diaminobenzidina), adicionado de peróxido de hidrogênio $0,2 \%$ em tampão PBS. 


\section{RESULTADOS}

\subsection{Varredura de tampões}

Por meio da varredura de tampões chegou-se a uma condição de resolução máxima que evidenciou um pico entre a convulxina e a giroxina.

Nas Figuras 1 e 2 nota-se que os tampões acetato de sódio e citrato de sódio, respectivamente, não resultaram em uma boa resolução na separação de proteínas de alto peso molecular.

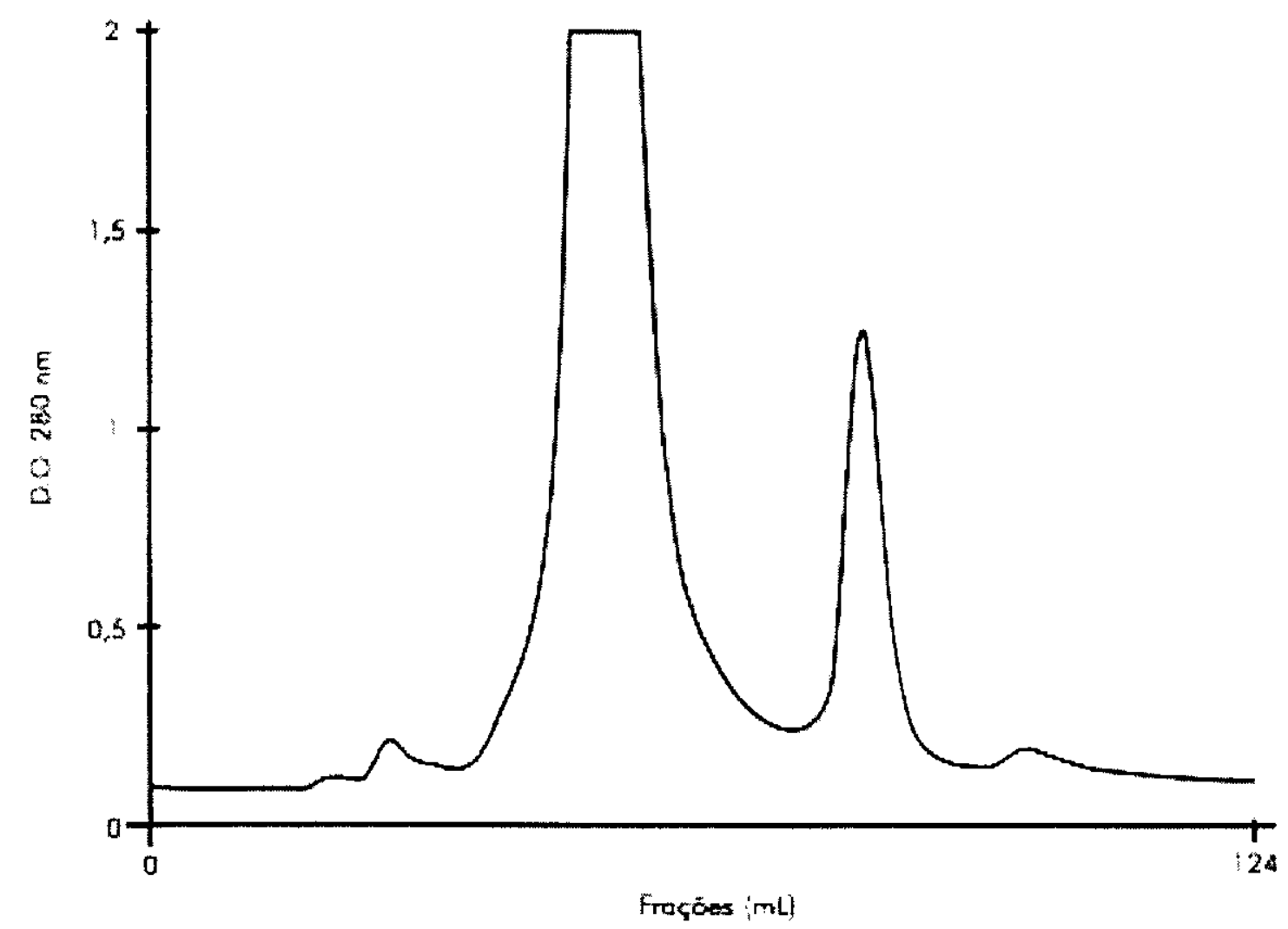

Figura 1. Perfil cromatográfico do veneno de C.d. terrificus em coluna Superdex 75. Tampão: Acetato de sódio $0,1 \mathrm{M} \mathrm{pH} \mathrm{5,0}$ 


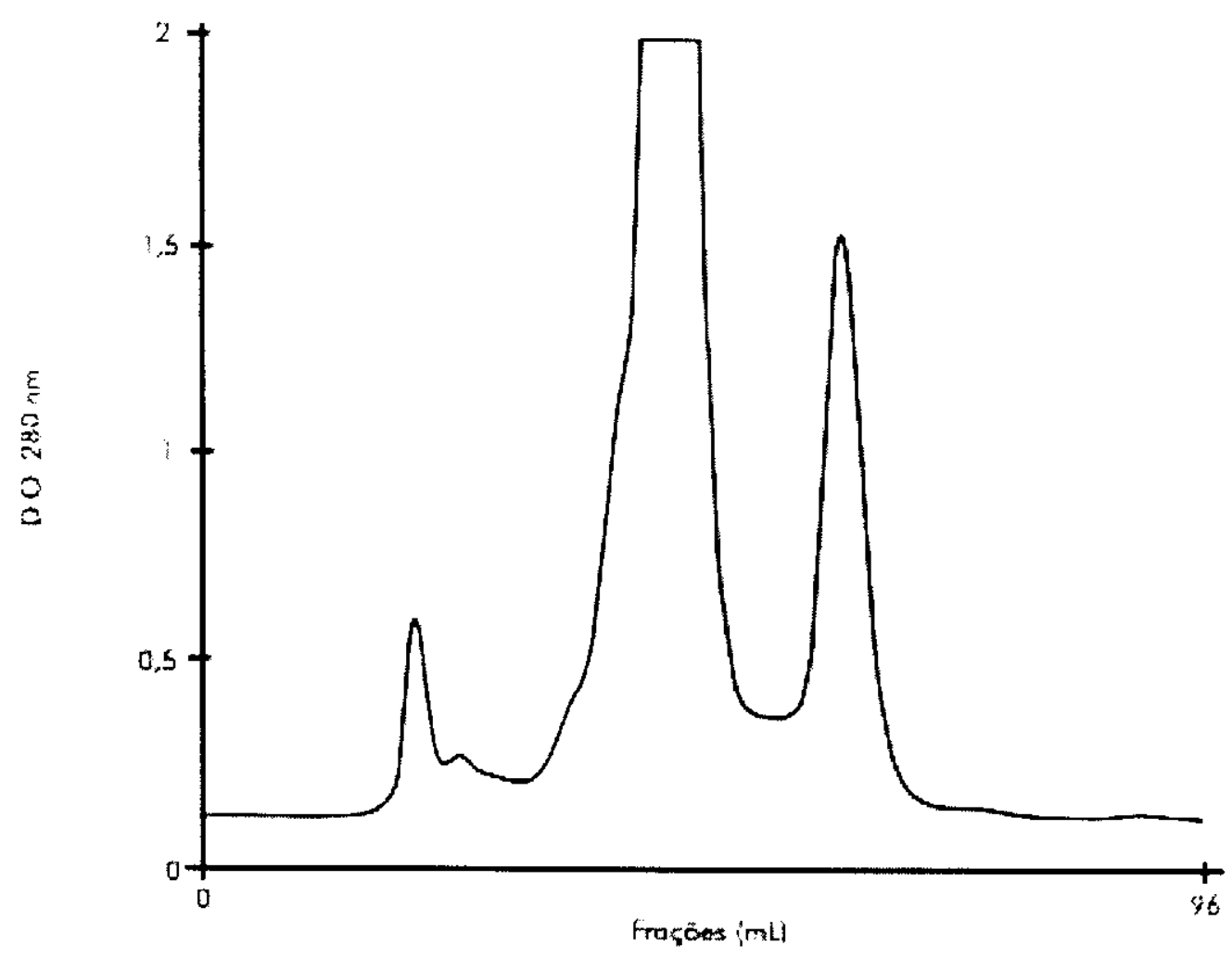

Figura 2. Perfil cromatográfico do veneno de C.d. terrificus em coluna Superdex 75. Tampão: Citrato de sódio $0,1 \mathrm{M}$ pH 5,0

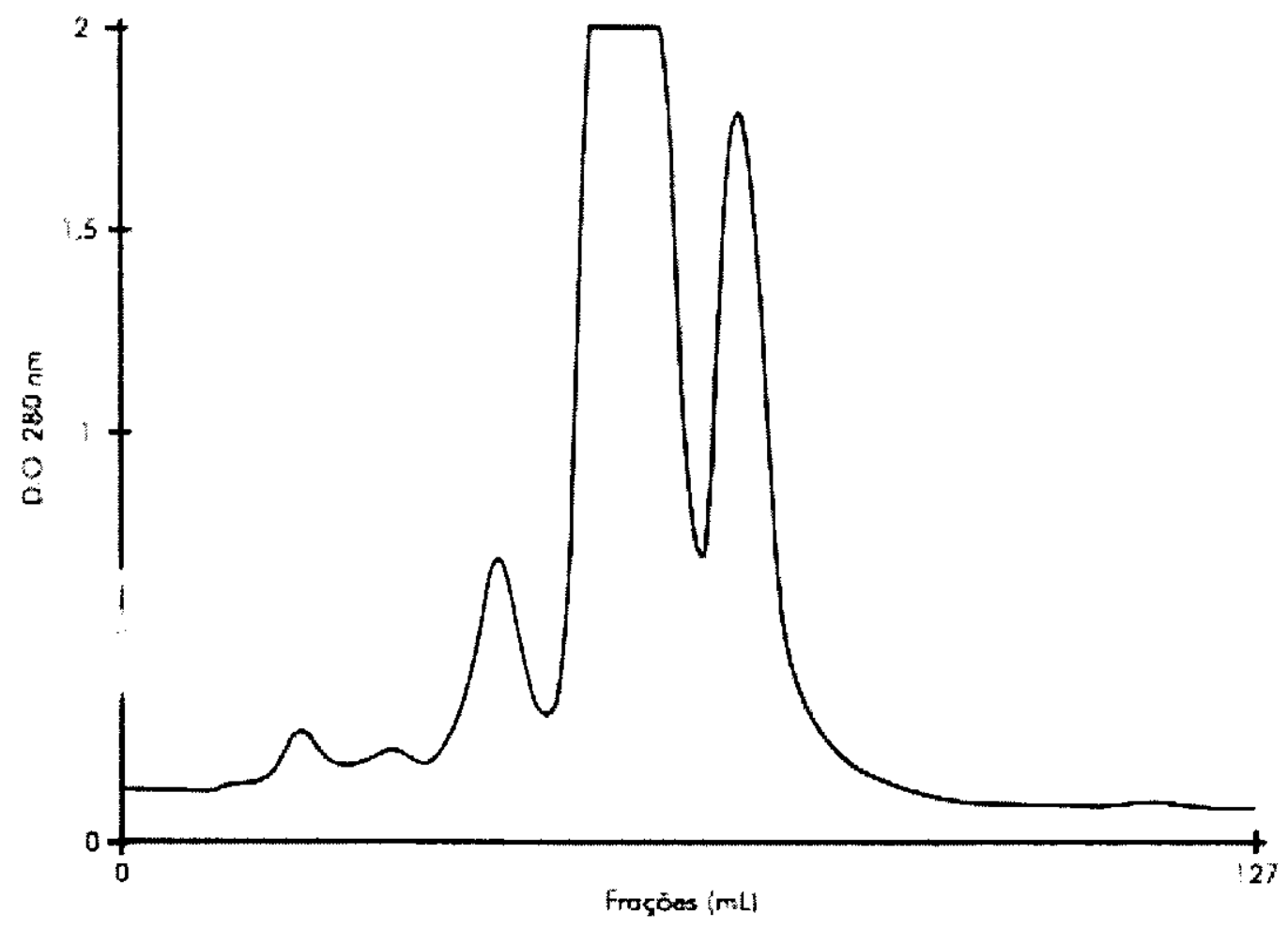

Figura 3. Perfil cromatográfico do veneno de C.d. terrificus em coluna Superdex 75. Tampão: Formiato de amônio $0,1 \mathrm{M} \mathrm{pH} 3,0$ 
A Figura 3 evidencia que a natureza do tampão é de grande importância para uma melhor separação de proteinas de alto peso molecular.

\subsection{Purificação do veneno crotálico (FPLC) - Exclusão Molecular}

Após a padronização das técnicas de purificação, sucessivas cromatografias com o veneno crotálico foram realizadas para a obtenção de uma quantidade de proteina suficiente para os ensaios posteriores.

\subsection{Cromatografia de fase reversa (HPLC)}

Para a obtenção da proteina pura, uma segunda etapa de purificação foi realizada em sistema HPLC. Após a identificação do tempo de retenção na fase reversa da giroxina e da convulxina que são os contaminantes após fracionamento em FPLC, foi possivel identificar isoladamente 0 pico correspondente á delta toxina (Figura 4).

Após a identificação do tempo de retenção, corridas subseqüentes foram realizadas. A primeira etapa de purificação em HPLC resultou no isolamento da delta toxina sem a contaminação de giroxina e convulxina (Figura 5 A). Após a repurificação das amostras em uma segunda etapa de cromatografia em HPLC, comprovou-se a pureza da proteina (Figura 5 B). 


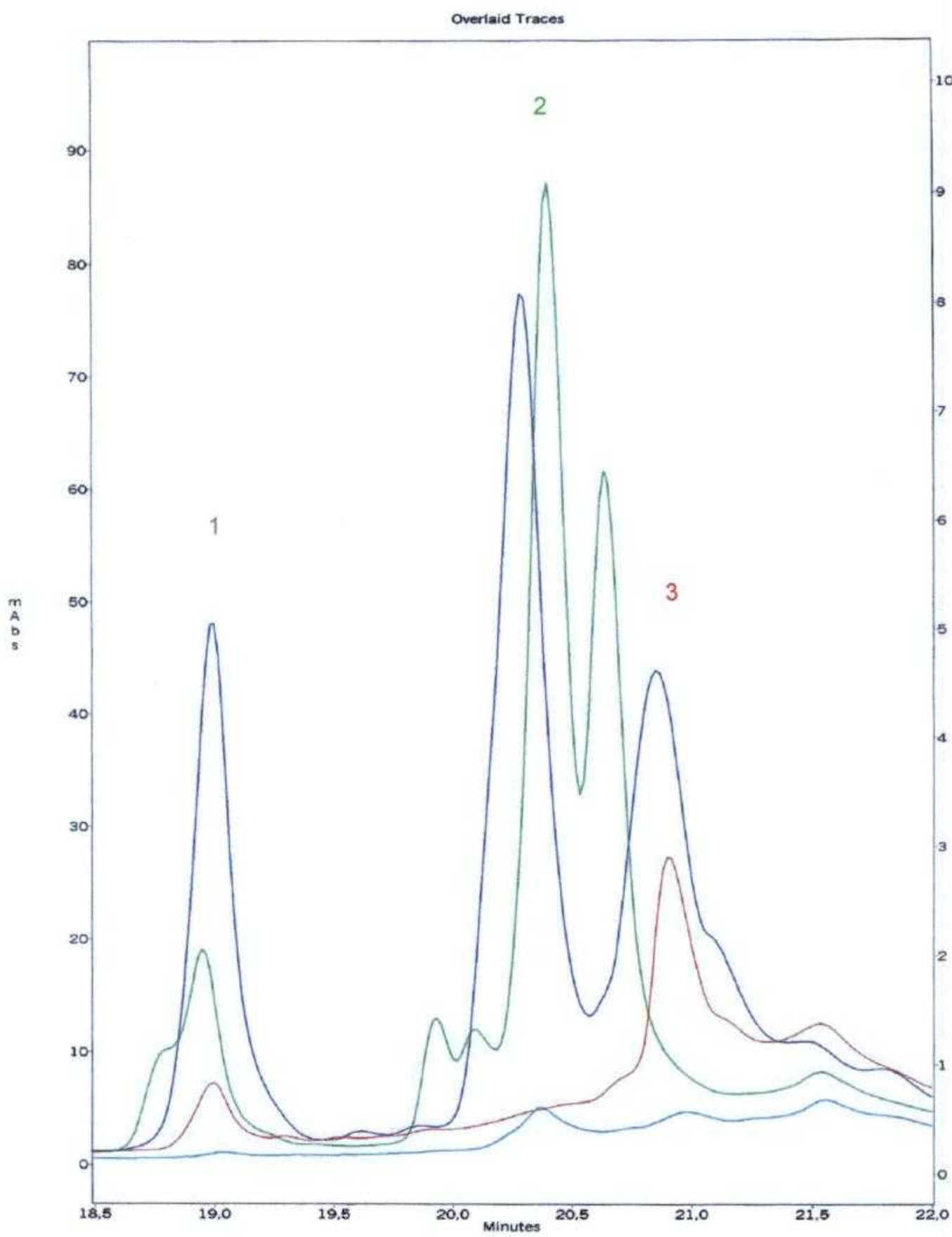

Figura 4. Perfil cromatográfico da purificação em sistema HPLC em coluna de fase reversa. Leitura em 220nm. Picos : (1) deltatoxina, (2) giroxina e (3) convulxina. 


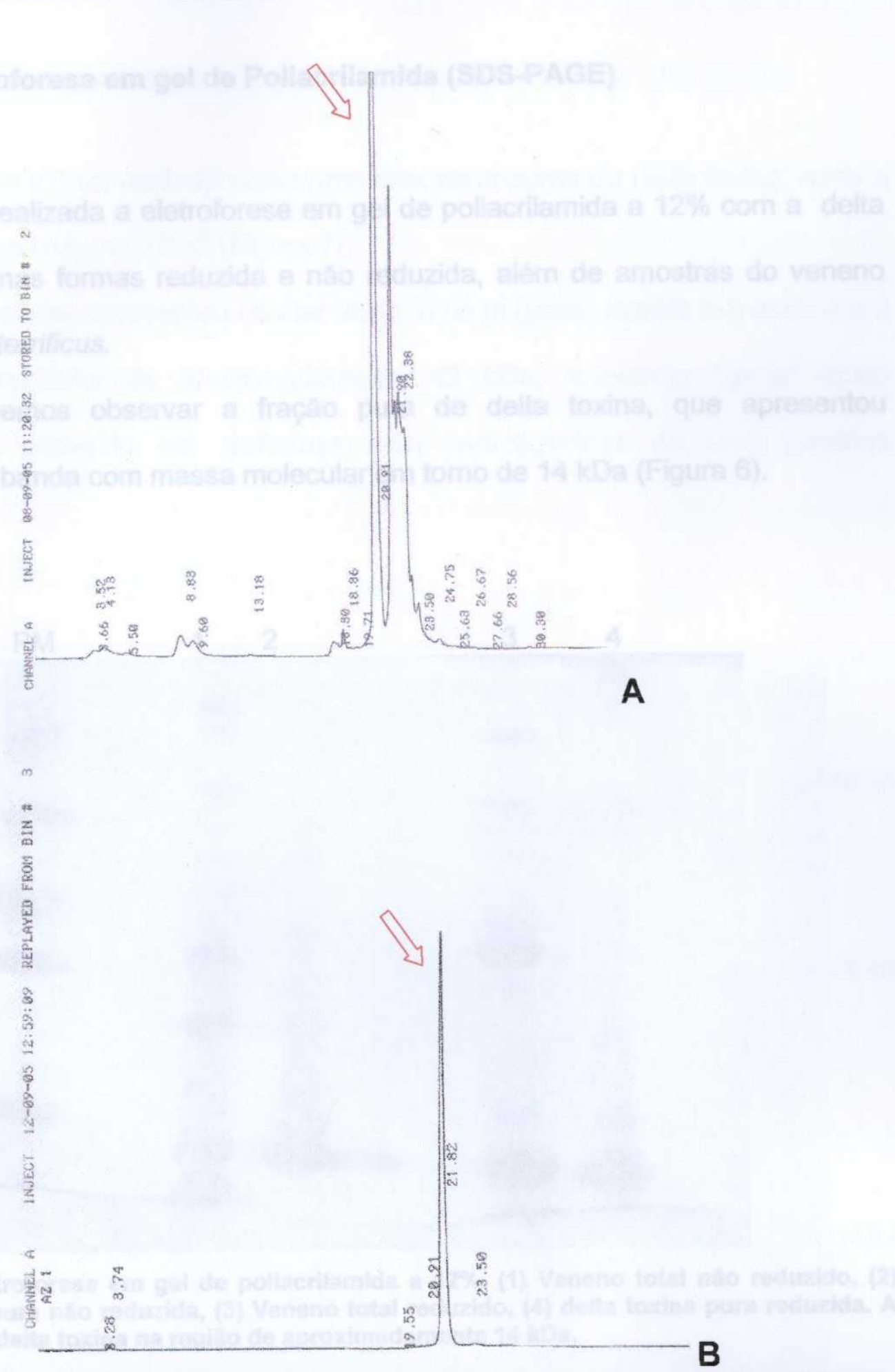

Figura 5. (A) Perfil cromatográfico da primeira etapa de purificação em sistema HPLC da delta toxina pós gel filtração. (B) Obtenção da proteína pura na segunda etapa de purificação em RP-HPLC. 


\subsection{Eletroforese em gel de Poliacrilamida (SDS-PAGE)}

Foi realizada a eletroforese em gel de poliacrilamida a $12 \%$ com a delta toxina pura, nas formas reduzida e não reduzida, além de amostras do veneno total de C.d. terrificus.

Podemos observar a fração pura de delta toxina, que apresentou apenas uma banda com massa molecular em torno de $14 \mathrm{kDa}$ (Figura 6).

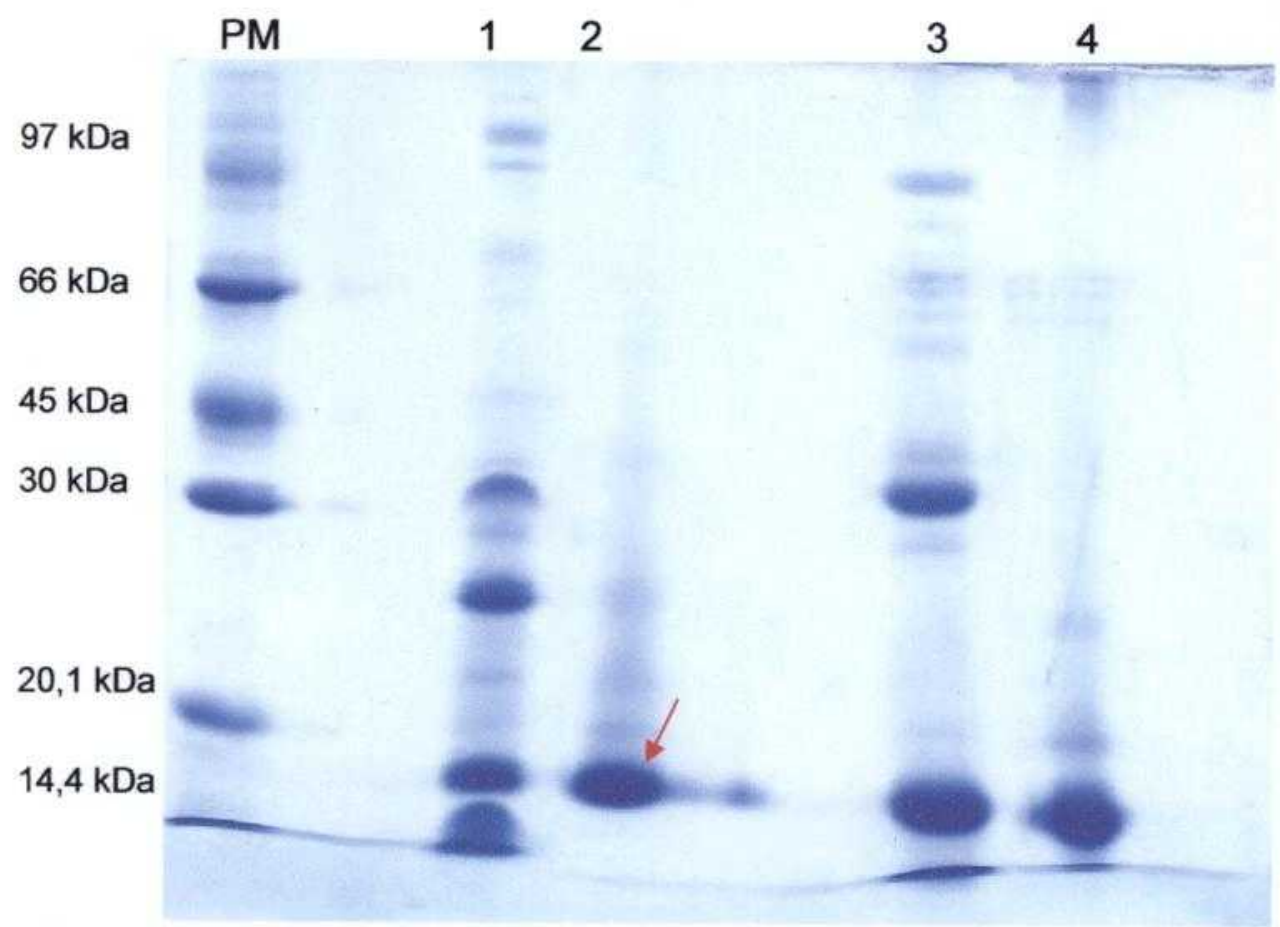

Figura 6. Eletroforese em gel de poliacrilamida a $12 \%$. (1) Veneno total não reduzido, (2) delta toxina pura não reduzida, (3) Veneno total reduzido, (4) delta toxina pura reduzida. A seta indica a delta toxina na região de aproximadamente $14 \mathrm{kDa}$. 


\subsection{Eletroforese Bidimensional}

O Gel 2D foi realizado com amostras semi-puras de delta toxina, após a purificação em sistema FPLC (Figura 7).

A proteina apresentou caráter ácido, e de pl (ponto isoelétrico) entre 4 e 5 e massa molecular de aproximadamente $42 \mathrm{kDa}$, revelando "spots" muito semelhantes podendo ser isoformas com características de uma proteina glicosilada.

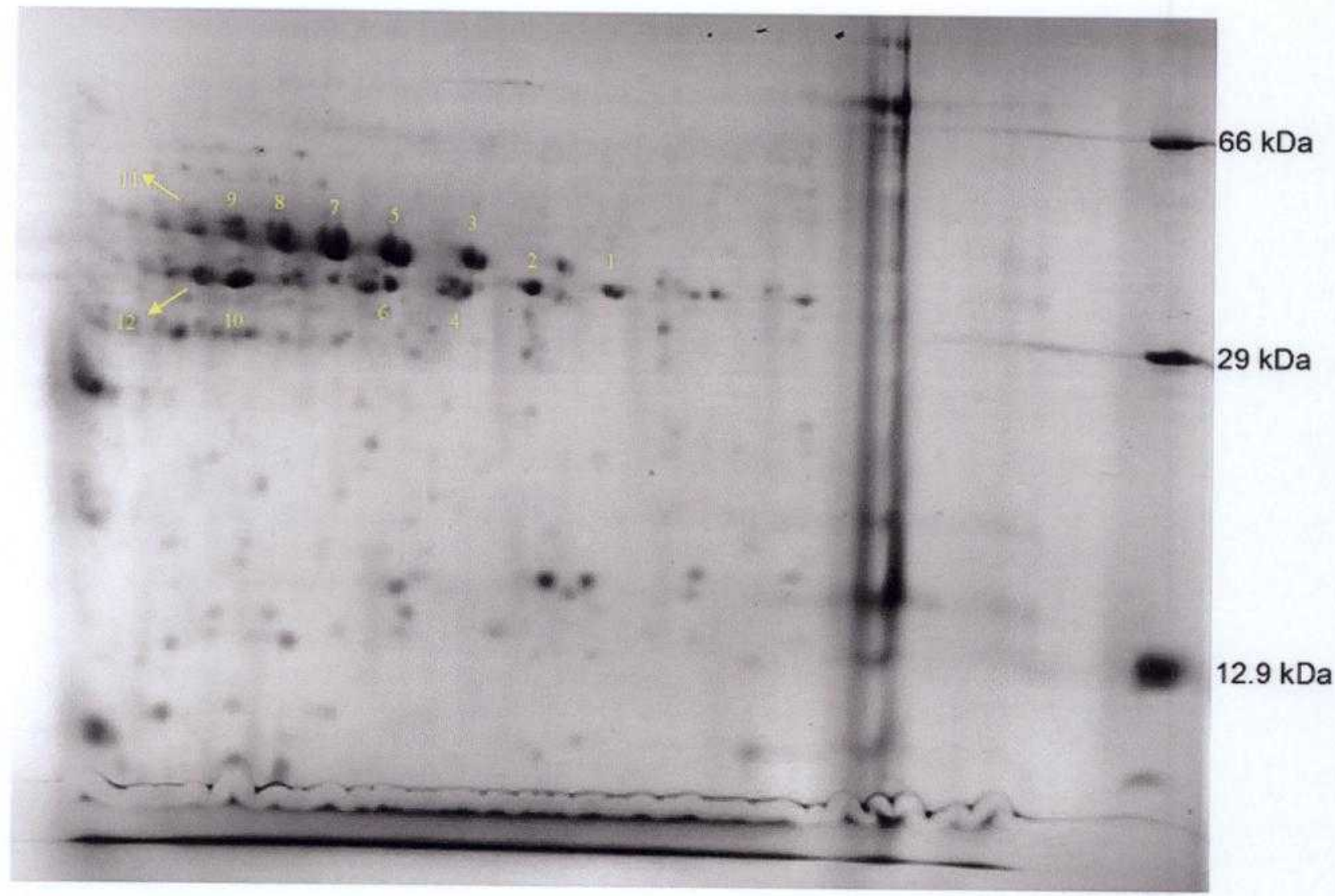

Figura 7. Eletroforese Bidimensional em gel de poliacrilamida a $15 \% \mathrm{com} 1 \mathrm{mg}$ de amostra da delta toxina semi-pura (pós gel filtração) aplicada em uma tira de $18 \mathrm{~cm}$ com gradiente de $\mathrm{pH}$ entre 4 e 7 . Spots ácidos com pl entre 4 e 5 e massa de aproximadamente $42 \mathrm{kDa}$. 


\subsection{Seleção dos Spots e Peptide Mass fingerprint por MALDI-ToF}

Os spots foram então extraídos do gel um a um e após passarem por um processo de digestão com tripsina, foi realizada uma análise dos fragmentos peptídicos no espectrômetro de massa (MALDI-ToF) sendo os peptídeos resultantes confrontados com banco de dados do "swissprot" utilizando o software MASCOT. A análise por Peptide mass fingerprinting (Figura 8), correlaciona massas peptídicas geradas pela digestão da proteína com as massas peptídicas teoricamente esperadas.

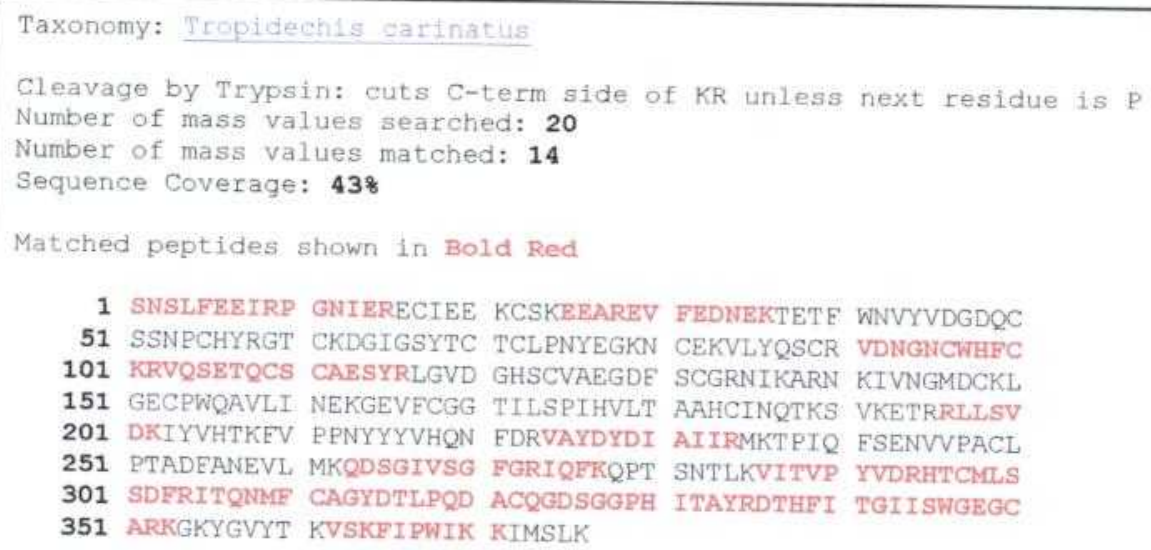

Figura 8. Análise dos fragmentos trípticos por Mass Fingerprinting comparados com a trocarina, proteina isolada do veneno de Tropidechis carinatus

A análise dos fragmentos trípticos e sua confrontação com o banco de dados sugere alto grau de homologia com a trocarina (Joseph J.S. et al. 1999), um ativador de protrombina do veneno de Tropidechis carinatus, tendo sido obtidos 14 fragmentos coincidentes cobrindo $43 \%$ da seqüência descrita (Figura 8). 


\subsection{MALDI-ToF}

A análise da amostra semi-pura da delta toxina apresentou os contaminantes esperados, a giroxina representado pelo segundo envelope de massa com aproximadamente $29 \mathrm{kDa}$, e convulxina representada pelo terceiro envelope de massa, com $60 \mathrm{kDa}$. A delta toxina apresentou massa em torno de $14 \mathrm{kDa}$ (Figura 9).

A análise da amostra pura por MALDI-ToF aponta para uma alta pureza do material cuja a massa foi estimada em 14074,92 Da (Figura 10), validando o método de purificação utilizado. Acredita-se que o envelope de massa majoritário representa uma subunidade da delta toxina com carga $+1(M=14074,92)$ sendo os outros dois o Homodímero $(M=28370,068)$ e o Homotrímero $(M=42799,514)$. 


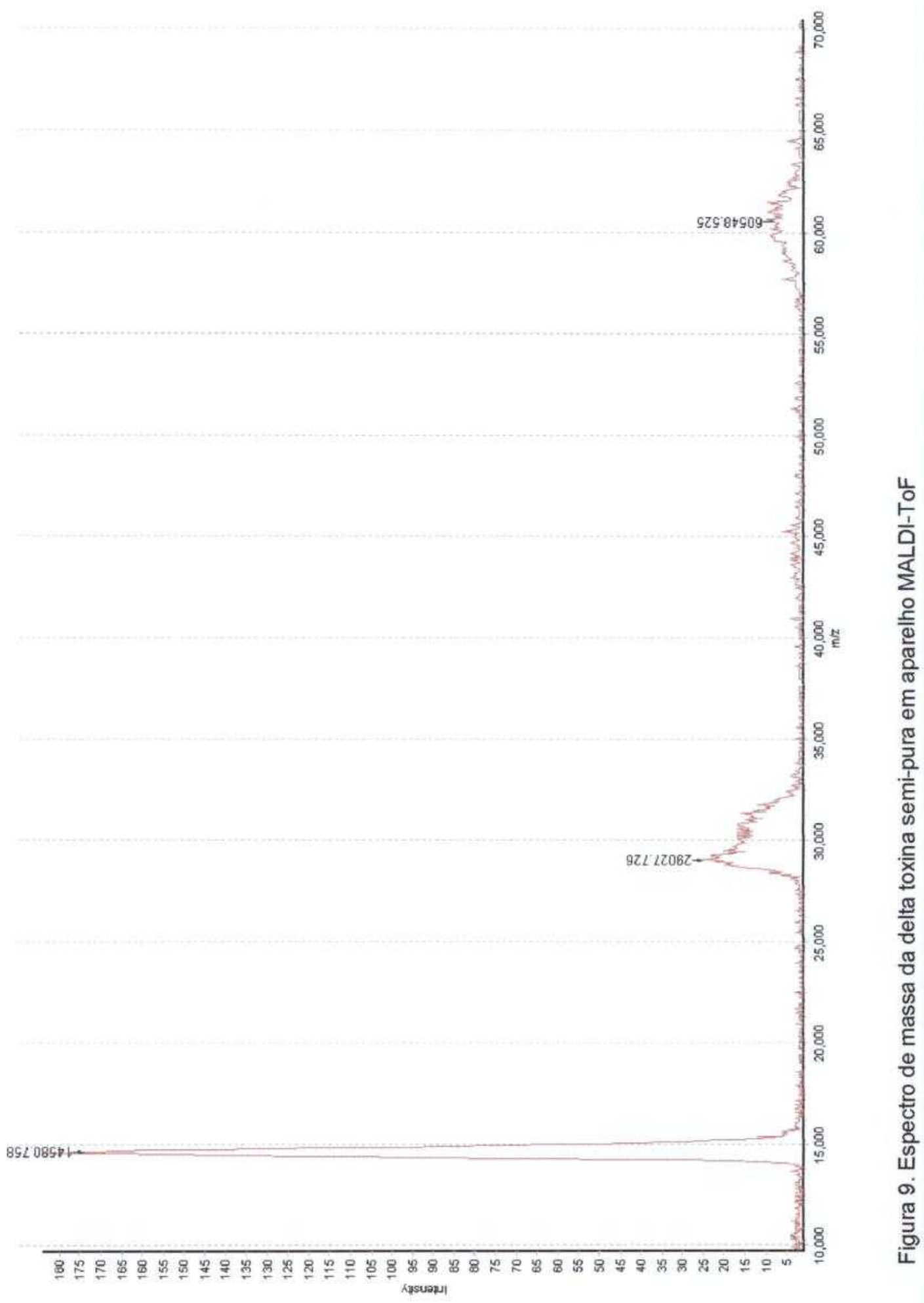




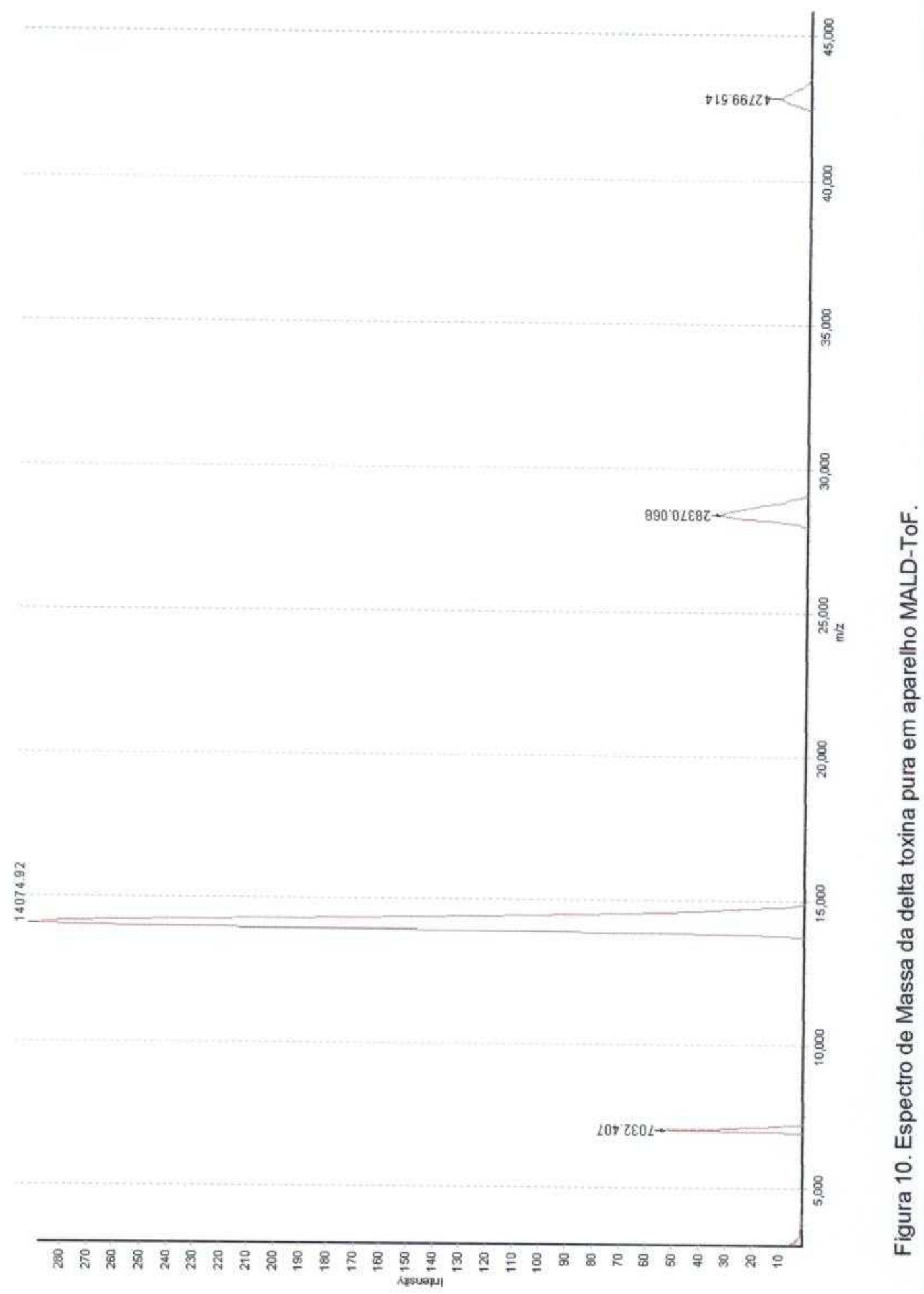




\subsection{Análise de Aminoácidos}

Padrão

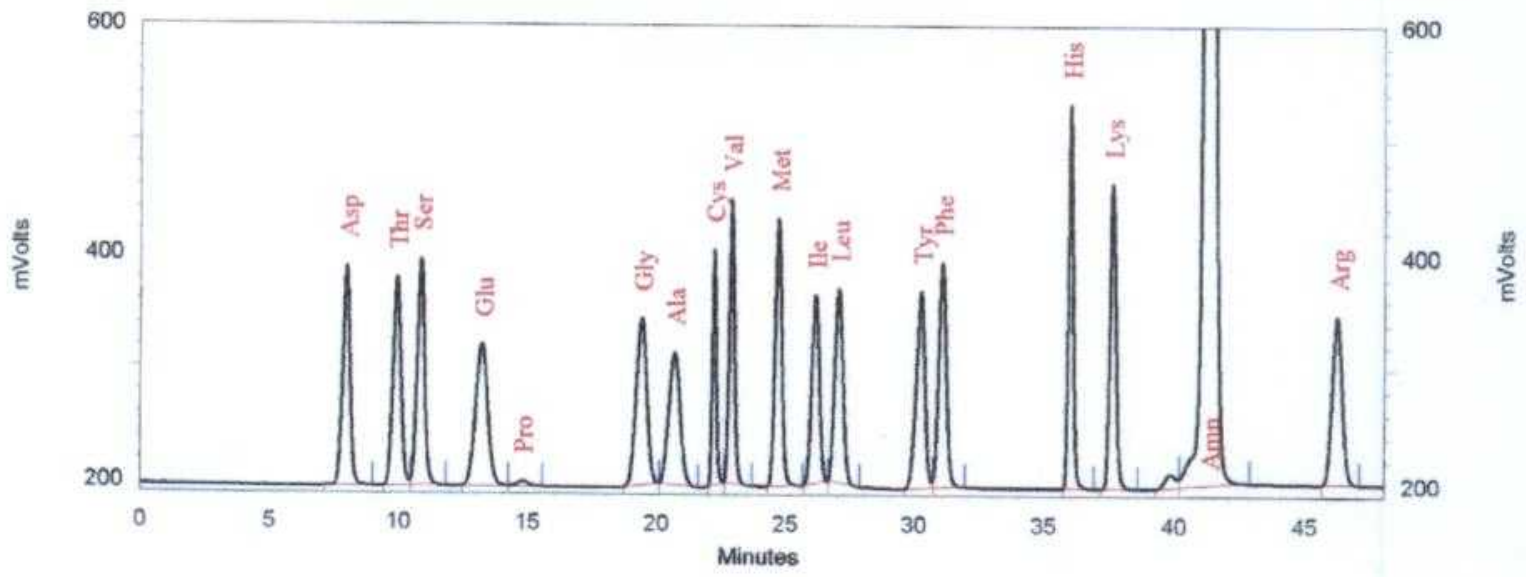

Delta toxina

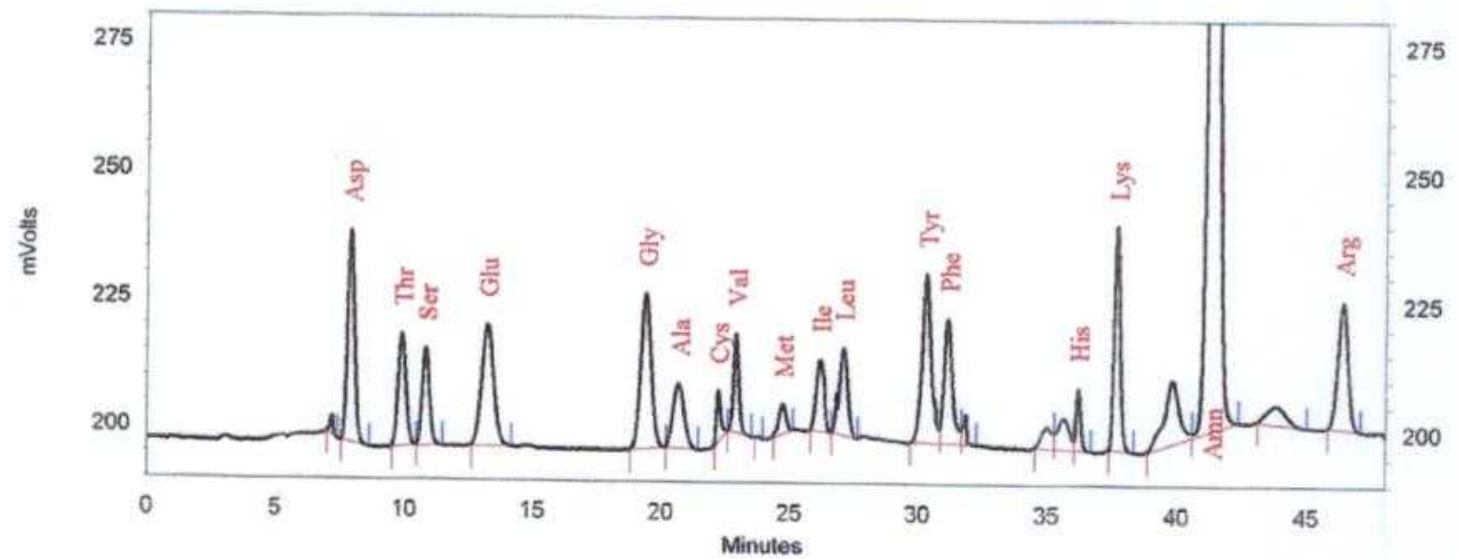

Figura 11. Análise de aminoácidos. Perfil cromatográfico doa aminoácidos do padrão e da delta toxina após derivatização com ninidrina.

Com os dados da análise de aminoácidos (figura 11) e com o cálculo do percentual molar (Tabela 1), foi possivel confrontar os resultados com o banco de dados do "swissprot" e confirmar os resultados da análise dos spots do gel 2D.

Os dados gerados apresentaram o mesmo grau de homologia com a trocarina (Joseph J.S. et al. 1999), uma serino protease de uma serpente australiana. 


\begin{tabular}{c|c|c|c}
\hline Aminoácidos & $\begin{array}{c}\text { Área } \\
\text { Padräo }\end{array}$ & $\begin{array}{c}\text { Área } \\
\text { amostra }\end{array}$ & $\begin{array}{c}\text { Percentual } \\
\text { Molar }\end{array}$ \\
\hline Asx & 3941832 & 779096 & 8,7950 \\
\hline Thr & 3986475 & 475041 & 5,2770 \\
\hline Ser & 4089028 & 385284 & 4,3975 \\
\hline Glx & 4133915 & 772379 & 8,7950 \\
\hline Pro & 143409 & & n.d. \\
\hline Gly & 4203395 & 851890 & 8,7950 \\
\hline Ala & 3398983 & 387180 & 5,2770 \\
\hline Cys & 2180792 & 109774 & 2,1987 \\
\hline Val & 3550609 & 289110 & 3,5180 \\
\hline Met & 4280053 & 111251 & 1,1433 \\
\hline lle & 3422005 & 306589 & 4,3975 \\
\hline Leu & 3781238 & 406165 & 4,7493 \\
\hline Tyr & 4028273 & 816718 & 8,7950 \\
\hline Phe & 4067541 & 556870 & 6,1565 \\
\hline His & 4242955 & 157162 & 1,7590 \\
\hline Lys & 4292708 & 689462 & 7,0360 \\
\hline Amn & 25199650 & 6493464 & 11,4335 \\
\hline Arg & 3906100 & 663947 & 7,4758 \\
\hline Pro & 980639 & 1322 & n.d.
\end{tabular}

Tabela 1. Cálculo do percentual molar de cada aminoácido. realizada a partir da área dos picos da amostra de delta toxina e do padrão.

\subsection{Agregação Plaquetária}

Nos ensaios de agregação plaquetária, a delta toxina mostrou-se próagregantes sobre plaqueta lavada (PL). Na figura 11 a delta toxina está representada no primeiro canal em preto, o canal azul e o segundo canal preto mostram a agregac $\approx$ jaquetas após a adição de colágeno. A delta toxina foi capaz de in . egação plaquetária de forma eficiente, pois apresentou resultar. ante ao do controle positivo. 


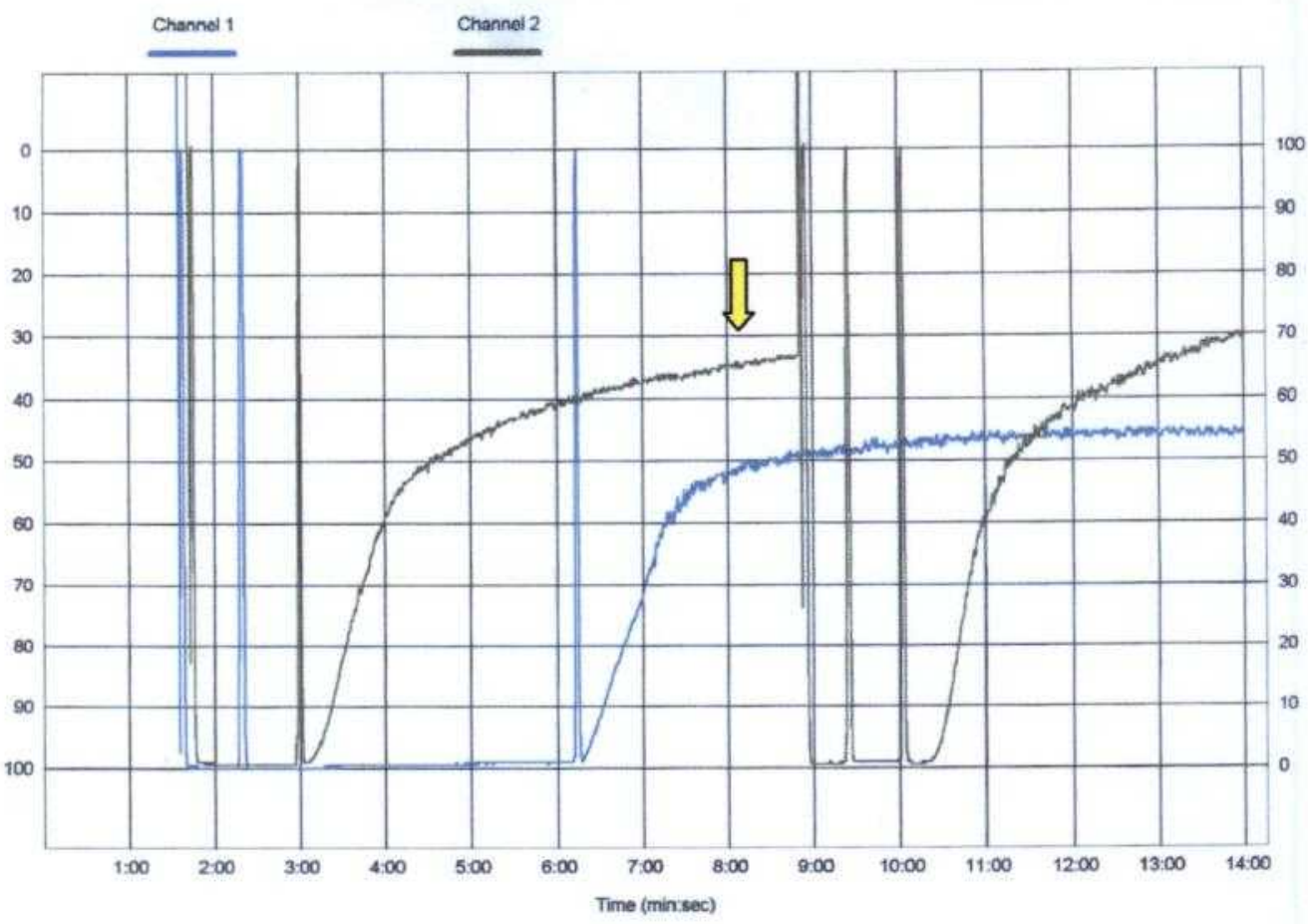

Figura 12. $1^{\circ}$ canal preto: $400 \mu \mathrm{L}$ de $\mathrm{PL}+90 \mu \mathrm{L}$ de delta toxina $(144 \mu \mathrm{g} / \mathrm{mL})$;

$1^{\circ}$ canal azul: $400 \mu \mathrm{L}$ de $\mathrm{PL}+90 \mu \mathrm{L}$ de PBS $+10 \mu \mathrm{L}$ de colágeno $(10 \mu \mathrm{M})$; $2^{\circ}$ canal preto: $400 \mu \mathrm{L}$ de $\mathrm{PL}+90 \mu \mathrm{L}$ de PBS $+10 \mu \mathrm{L}$ colágeno $(10 \mu \mathrm{M})$ 
$\mathrm{Na}$ figura 13 a delta toxina mostrou-se eficiente na agregação plaquetária mesmo em concentrações muito menores, de 2,7 e $0,9 \mu \mathrm{g} / \mathrm{mL}$, representados nos canais 1 e 2 respectivamente.

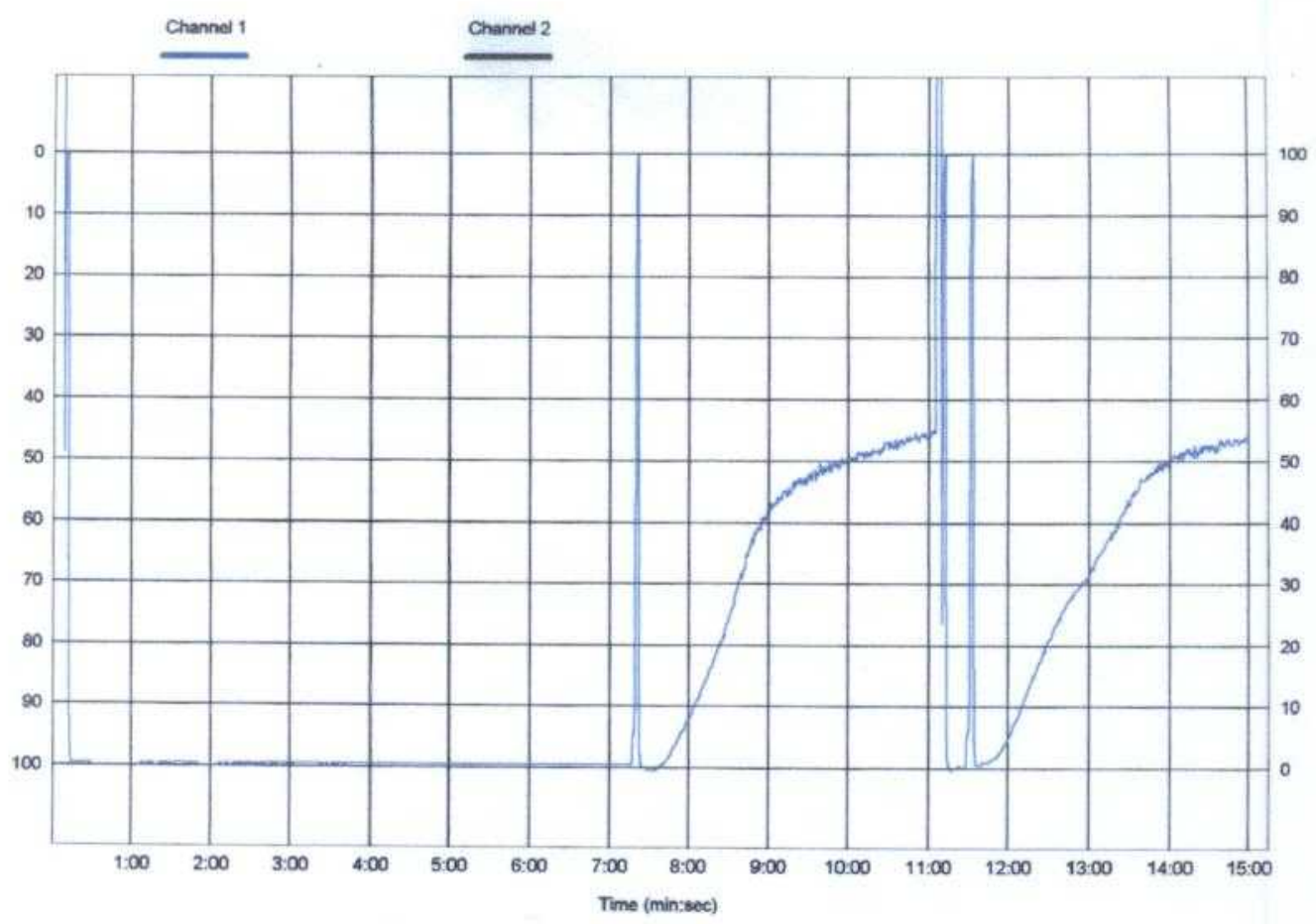

Figura 13. Canal 1 azul: $400 \mu \mathrm{L}$ de $\mathrm{PL}+90 \mu \mathrm{L}$ de delta toxina $(2,7 \mu \mathrm{g} / \mathrm{mL})$ Cabal 2 azul: $400 \mu \mathrm{L}$ de $\mathrm{PL}+90 \mu \mathrm{L}$ de delta toxina $(0,9 \mu \mathrm{g} / \mathrm{mL})$

\subsubsection{Inibidores de serino, metalo proteinases e lectinas.}

Para a caracterização dessa nova toxina que atua de forma agonista na agregação plaquetária, foram realizados experimentos para testar a atividade da delta toxina sobre plaqueta lavada, na presença de inibidores de serino, metalo proteinases e lectina. 


\begin{tabular}{|c|c|c|}
\hline 400 uL de Plaqueta lavada + & Agregou & Não Agregou \\
\hline 90 uL de Delta toxina (18ug) & $x$ & \\
\hline 90 uL de PBS + 10uL de colágeno & $x$ & \\
\hline 90 uL de Delta toxina (PMSF 5mM) & & $\mathrm{X}$ \\
\hline 90 uL PBS (PMSF 5mM)+ Colágeno & & $x$ \\
\hline $90 \mathrm{uL}$ de Delta toxina ( EDTA $5 \mathrm{mM}$ ) & $x$ & \\
\hline $90 \mathrm{uL}$ de PBS (EDTA 5mM) & & $x$ \\
\hline 90 uL de Delta toxina (o-phe $5 \mathrm{mM}$ ) & & $x$ \\
\hline $90 \mathrm{uL}$ de PBS (o-phe $5 \mathrm{mM})+10$ uL de colágeno & & $\mathrm{X}$ \\
\hline $90 \mathrm{uL}$ de Delta toxina (D-galac $5 \mathrm{mM}$ ) & $x$ & \\
\hline 90 uL de Delta toxina (D-galac $16 \mathrm{mM}$ ) & $x$ & \\
\hline 90 uL PBS (D-galac 5mM) & & $x$ \\
\hline 90 uL de Delta toxina (benxamidina $5 \mathrm{mM}$ ) & $x$ & \\
\hline 90 uL de PBS (benzamidina $5 \mathrm{mM}$ ) + colágeno & $x$ & \\
\hline 90 uL de Delta toxina (benxamidina $25 \mathrm{mM}$ ) & $x$ & \\
\hline 90 uL de PBS (benzamidina $25 \mathrm{mM}$ ) + colágeno & $x$ & \\
\hline
\end{tabular}

Tabela 2. Ensaio de agregaçāo plaquetária com a delta toxina na presença de inibidores de serino, metalo proteinase e lectina em diversas molaridades.

Com os ensaios de agregação plaquetária na presença de alguns inibidores como o EDTA foi possivel observar que esse inibidor não foi eficaz, assim sugerindo que essa proteina não seja uma metalo proteinase. O mesmo aconteceu com um inibidor de lectina, o açúcar d-galactose, sugerindo que a agregação induzida pela toxina seja independente de interação com dominios glicosilados. Da mesma forma, a benzamidina, um inibidor clássico de serinoproteinases, não interferiu na atividade agregante, sugerindo que a atividade sobre plaquetas independe deste mecanismo catalítico. 
Já com a 1-10 fenantrolina e com o PMSF não obtivemos resultados confiáveis uma vez que esses inibidores por si só interferem na atividade da plaqueta, inibindo sua agregação, mesmo com a adição posterior do colágeno (Tabela 2).

\subsection{Ativador de fator $X$}

No ensaio de ativador de fator $X$, verificou-se que tanto o veneno total de C.d. terrificus como as frações, semi-pura e pura de delta toxina apresentaram atividade ativadora de fator $\mathrm{X}$ significante, após 25 minutos de incubação como mostra a Figura 14.

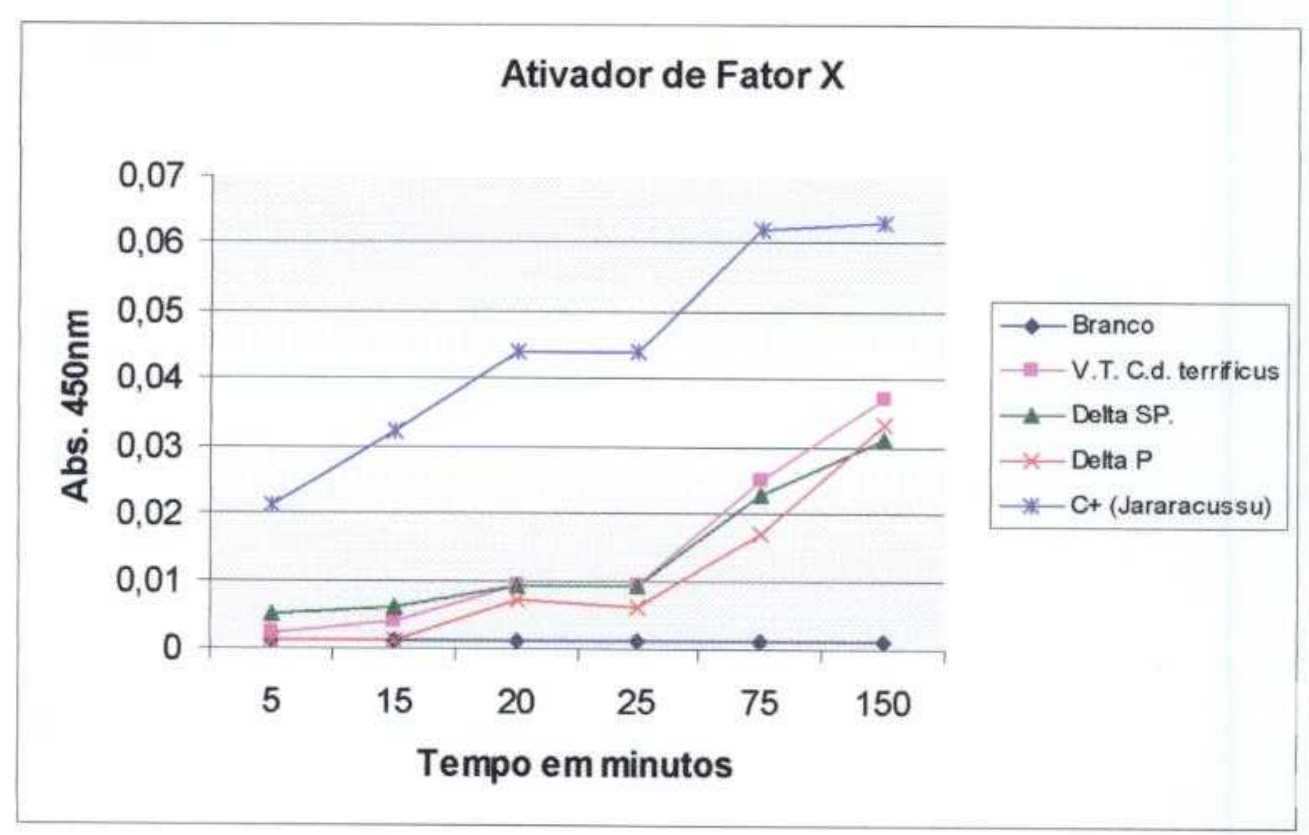

Figura 14. Teste de ativador de Fator $X$ com amostras de delta toxina semi-pura, pura e veneno total de C.d. terrificus. Controle positivo com veneno de $B$. jararacussu. 


\subsection{Ativador de Fator II}

Esse ensaio foi realizado para avaliar se a atividade ativadora de fator $X$ era decorrente da ação direta da toxina ou se a mesma ativava fator II, que por sua vez levava a conversão de protrombina em trombina. Como se observa na Figura 15 a delta toxina não ativou o fator II. Amostras de delta toxina semi-pura e veneno total também não apresentaram atividade ativadora de fator II.

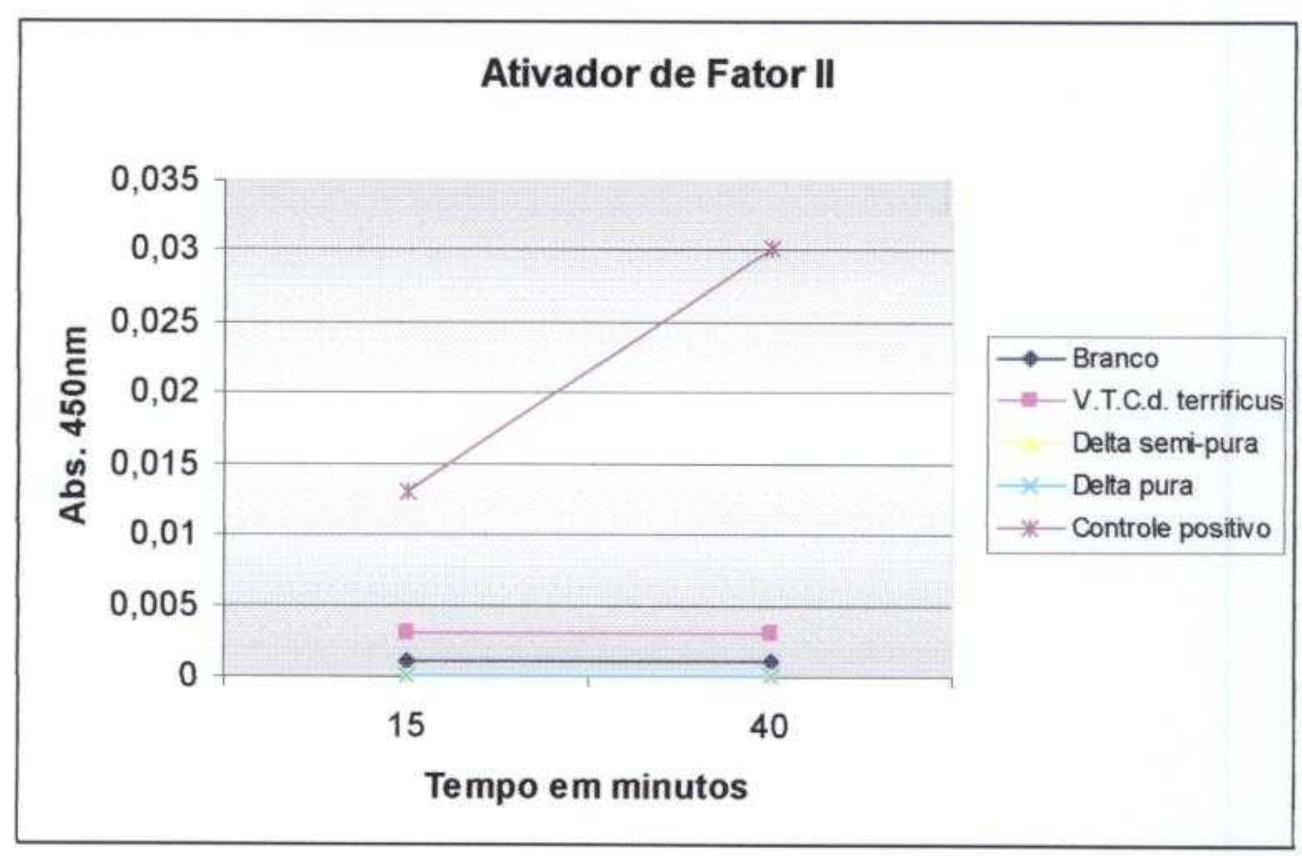

Figura 15. Teste de ativador de Fator II com amostras de delta toxina semi-pura, pura e veneno total de C.d. terrificus. Controle positivo com veneno de B. jararacussu. 


\subsection{Western Blotting}

A análise por western blot (Figura 16) indicou que o anti-soro comercial foi capaz de reconhecer a delta toxina em sua forma não reduzida e reduzida. Tal fato indica que a toxina é imunogênica e que induz anticorpos capazes de reconhecer tanto epitopos contínuos quanto conformacionais.

PM

12

3

4

Figura 16. Western blotting com o veneno total e a delta toxina pura, em condições não redutoras e redutoras. 


\section{DISCUSSÃO}

O veneno de Crotalus durissus terrificus, tem sido amplamente estudado mas ainda possui componentes quase desconhecidos. A composição do veneno crotálico é complexa e constituída de enzimas, toxinas. peptídios e outros componentes (Takeda et al., 1985, Barraviera, 1994).

Por meio da varredura de tampões, no fracionamento do veneno por cromatografia de exclusão molecular, chegou-se a uma condição de resolução máxima que evidenciou um pico entre a convulxina e a giroxina. A existência de um componente nesta posição, como foi sugerido por Vital Brasil em 1980, não havia ainda sido comprovada. A varredura de tampões não só identificou o pico citado como possibilitou a purificação e caracterização de uma nova toxina do veneno de Crotalus durissus terrificus.

Os tampões acetato de sódio e citrato de sódio não resultaram em uma boa resolução na separação de proteinas de alto peso molecular. No entanto o tampão formiato de amônio mostrou que a natureza do tampão é de grande importância para uma melhor separação de proteinas de alto peso molecular, pois apresentou uma maior resolução. Acredita-se que tal resultado seja fruto da conjugação de $\mathrm{pH}$ e força iônica ideal. Técnicas de purificação por troca iônica e interação hidrofóbica não perr . . 0 isolamento da toxina.

Para a obter . da : Jteína pura, uma segunda etapa de purificação foi realizada em sistema HPLC. Essa etapa de purificação tem sido usada como alternativa para o isolamento de proteinases (Serrano \& Maroun, 2005). Após a identificação o tempo de retenção na fase reversa da giroxina e da convulxina 
que são os contaminantes após fracionamento em FPLC, tornou-se possivel identificar isoladamente o pico correspondente á fração de interesse. De acordo com as condições do gradiente e tempo de eluição, concluiu-se que a proteína é bastante hidrofóbica. Após as passagens de purificação e de liofilização da amostra, pôde-se chegar a uma quantidade muito pequena de proteina pura, representada por $0,2 \%$ do peso seco do veneno total. Para efeito de comparação, a trocarina, uma serino proteinase pertencente ao grupo $D$ de ativadores de protrombina, representa $5 \%$ do veneno total sendo uma proteina glicosilada (Kini, 2005).

$\mathrm{Na}$ análise em eletroforese em gel de poliacrilamida pode-se observar que a delta toxina apresentou massa molecular de cerca de $14 \mathrm{kDa}$ e uma migração anômala, o valor da massa molecular da delta toxina foi compativel com os resultados obtidos na análise em espectrometria de massa, podendo ser essa proteína um homotrímero de massa total de aproximadamente $42 \mathrm{kDa}$. Paralelamente procedeu-se uma análise da fração semi-pura. por eletroforese bidimensional.

Esse método permite analisar subgrupos específicos de uma toxina, além da possibilidade de análise da complexidade da amostra (Serrano et al., 2005). Com a análise do Gel 2D, a proteína apresentou caráter ácido, e de pl entre 4 e 5 e massa molecular de aproximadamente $42 \mathrm{kDa}$, revelando "spots" muito semelhantes podendo ser isoformas com características de uma proteina glicosilada. Em ensaios de análise de aminoácidos a proteína apresentou características típicas de glicosilação ao formar um "peliet" marrom após ser submetida à hidrólise ácida com $\mathrm{HCl} 6 \mathrm{~N}$. A função da glicosolação em serino 
proteinases de venenos ofídicos não é bem conhecida. Recentes estudos com uma protease A de Bothrops, uma serino proteinase, composta por $60 \%$ de carboidratos do total da massa molecular, indicam que a glicosilação tem efeito estabilizante sobre as proteases, que resistem à hidrólise de proteinases (Jin et al. , 2005).

Cerca de 12 "spots", todos ácidos e com massa molecular em torno de $40 \mathrm{kDa}$, foram selecionados para a digestão com tripsina para a identificação por análise dos fragmentos peptídicos no espectrômetro de massa (MALDI-ToF). A maioria dos "spots" gerou fragmentos similares, sugerindo tratar-se da mesma proteina. Acredita-se que essa similaridade dos "spots" e dos fragmentos gerados possam ser atribuidos a microheterogeneidade decorrente de glicosilação. Tal hipótese é reforçada pelo fato da proteina ter um comportamento anômalo em SDS-PAGE assim como por eluir com arraste em purificação em coluna de trocaiônica.

Proteinas, com atividade na cascata da coagulação, são caracterizadas como ativadores de Fator $\mathrm{X}$, ativadores de protrombina e enzimas thrombine-like, podendo ser então uma serino ou metalo proteinases (Joseph J.S. et al. 2002). Todos os "spots" processados por fingerprint, quando confrontados com o banco de dados do "swissprot" mostraram alto grau de homologia "até $43 \%$ de cobertura" com a trocarina, um ativador de protrombina do veneno de Tropidechis carinatus (Joseph J.S. et al. 1999). Ao confrontar os dados da análise de aminoácidos com os bancos de dados, obteve-se, mais uma vez, a trocarina como proteína cuja composição era homóloga à da toxina em estudo. Cabe 
ressaltar que outra proteina, do veneno do $B$. jararaca, também apresentou homologia quando os fragmentos foram analisados in silico.

De posse desses resultados optou-se por testar a capacidade da fração purificada, de ativar fator $X$ e II, usando substratos sintéticos. A cinética da ativação do Fator $X$ foi medida pela atividade amidolitica de fator $X$ formado (Hofmann e Bon, 1987). Os resultados apontaram para uma ativação direta do fator X, uma vez que não houve ativação do fator II, atividade que também não foi detectada no veneno total. Dentre as proteinas procoagulantes de venenos de serpentes, ativadores de trombina são funcionalmente similares ao fator $\mathrm{Xa}$ da coagulação, assim como a trocarina, uma serino proteinase pertencente ao grupo D de ativadores de protrombina. (Joseph J.S. et al. 1999, Rao \& Kini, 2002).

Baseados em relatos de Vital Brazil (1980) sobre a delta toxina ser uma proteina que altera acentuadamente a permeabilidade vascular e causa grande hemoconcentração, testou-se a delta toxina em ensaios de agregação plaquetária. A mesma se mostrou um potente ativador da agregação de forma direta, uma vez que os ensaios foram realizados com plaquetas lavadas, logo na ausência de fatores séricos. Estudos com uma proteína isolada do veneno de Proatheris superciliaris, mostraram ser esta uma proteina agonista de agregação plaquetária, de $34 \mathrm{kDa}$. A proaterocetina ativou a agregação plaquetária na ausência de proteinas plasmáticas, demonstrando que esse efeito não pode ser atribuido a $\mathrm{m}$ ativador de fatores de coagulação. A proaterocetina foi caracterizada como uma serino proteinase (Laing et al, 2005).

A maioria dos venenos ofídicos coagulantes é caracterizada como proteinases que ativam especificamente fator $X$ ou protrombina ou convertem 
fibrinogênio em fibrina e são classificados como metalo ou serino proteinases. 0 grupo D das serino proteinases é estruturalmente e funcionalmente similar ao fator Xa, mas diferentemente do FXa de mamiferos, é constituido de glicoproteinas (Kini, 2005).

Para uma melhor caracterização da delta toxina, procedemos a ensaios posteriores usando inibidores específicos de metalo, serino proteinases e de lectinas. Nossos dados sugerem que, nem a atividade metalo proteinase, nem a serino proteinase, tampouco um dominio lectina estejam envolvidos no processo, uma vez que EDTA, benzamidina e D-galactose não inibiram a atividade da proteina. Metalo proteinases são caracterizadas pela inibição de sua atividade enzimática quando são expostas ao EDTA ou 1,10-Fenantrolina, ocorrendo a quelação do íon $\mathrm{Zn}{ }^{2+}$ por esses produtos (Matsui et al. 2000). No caso das serino proteinases os inibidores mais comuns são o PMSF (Fenil metil sulfonil fluoreto) e a benzamidina ( Matsui et al. 2000, Serrano \& Maroun, 2005).

Em testes com o PMSF e a 1,10-Fenatrolina os resultados não foram conclusivos, uma vez que nas concentrações utilizadas. o inibidor per se inibiu a agregação plaquetária induzida por colágeno. Esses inibidores são frequentemente utilizados em ensaios de coagulação ou atividade amidolítica com substratos sintéticos (Rosing \& Tans, 1992; Rao \& Kini, 2002).

Por fim, com os resultados do western blot, fica claro que a delta toxina possui propriedades imunogênicas e que induz anticorpos capazes de reconhecer tanto epitopos contínuos quanto conformacionais. Estes dados também sugerem que o soro neutraliza esta atividade. 


\section{CONCLUSÕES}

No presente trabalho, foi isolada uma nova toxina do veneno de $C$. $d$. terrificus, cuja existência já havia sido aventada, porém nunca demonstrada. De acordo com os dados aqui apresentados concluímos que:

- Trata-se de um ativador especifico de fator $X$.

- A mesma proteína ativa agregação plaquetária em concentrações muito baixas.

- De acordo com a análise em gel 2D trata-se de uma proteína ácida, com massa molecular em torno de $40 \mathrm{kDa}$.

- Quando analisada por espectrômetro de massa (MALDI), a toxina apresentou um envelope de massa majoritário de 14074,92 Da, levando-nos a crer que se trata de um homotrimero cujos componentes estão unidos por ligações fracas. 


\section{REFERÊNCIAS BIBLIOGRÁFICAS}

1 AEBERSOLD, R; MANN. M. Mass spectrometry-based proteomics. Nature, 422, p. 198-207, 2003.

2 AGUILAR, I., GIRÓN, M.E., RODRÍGUEZ-ACOSTA,A. Purification and characterization of a naemorrhagic fraction from the venom of the Uracosn rattlesnake Crotalus vegrandis. Biochimica et Biophysica Acta 1548 p: 57-65, 2001.

3 ALEXANDER, G.; GRATHUSEN, J.; ZEPEDA, H.; SCHWARTZMAN, R. J.; Gyroxin, a toxin from the venom of Crotalus durissus terrificus is a thrombin-like enzyme. Toxicon, 26 p. $953-960,1988$.

4 AMERShAM PHARMACIA BIOTECH, Protein Purification Handbook. Edição AB, Suécia, 1999.

5 AZEVEDO MARQUES, M.M., CUPO, P., HERING, S.E. "Plantas Venenosas e Animais Peçonhentos`- Samuel Schvartsman. Ed. Sarvier.161-167. São Paulo SP. 1992.

BAPTISTA, J.A. Aspectos da resposta imune frente a antigenos protéicos irradic: com ${ }^{60}$ Co. 2004. Dissertação (Mestrado) - Instituto de Pesquisas Energéticas e Nucleares, São Paulo.

7 BARRAVIERA, B "Venenos Animais" Uma visão integrada. Rio de Janeiro, R.J. Editora de Publicação Científica LTDA 1994.cap. 20, 281-295

8 BARRIO, A. A new toxin of Crotalus durissus terrificus venom. Acta. Physiol. Latinoamericana $11: 224,1961$.

9 BON, C.; CHANGEUX. J. P.; JENG, T.W. \& FRAENKEL-CONRAT, H. Postsynaptic effect of crotoxin and its isolated subunits. Eur. J. Biochem. 99 p. $471-481,1979$. 
10 BON, C.; RADVANYI, F.; SALOU, B. \& FAURE, G. - Crotoxin: a biochemical analysis of its mode of action. J. Toxicol. - Toxin Reviews $5 p-438-448,1986$.

11 CASARE, M.S. Influência das principais espécies reativas formadas durante o rocesso de destoxixação de toxinas por radiação ionizante. 2003. Sunitação (Mestrado) - Instituto de Pesquisas Energéticas e Nucleares, São Pain'

12 DELLA CASA, M. S. Caracterização estrutural e funcional da insularina, uma nova desintegrina do veneno de Bothrops insularis. 2004. Tese (Doutorado) - Instituto de Ciências Biomédicas, São Paulo.

13 DE PAULA, R.A., Obtenção e avaliação de anticorpos induzidos por veneno crotálico ou crotoxina irradiada em fonte de ${ }^{60} \mathrm{Co}$. 1995. Dissertação (Mestrado) - Instituto de Pesquisas Energéticas e Nucleares, São Paulo.

14 EDMAN, P.- Sequence determination. Mol. Biol. Biochem. Biophys., 8: 211-255, 1970.

15 FISCHER, L. Gel Filtration Chromatography. $2^{\text {nd }}$ edition, Elsevier, Amsterdan, 1990.

16 FUNASA ".. te diagnóstico e tratamento de acidentes por animais pescrnernos. Grasilia, 2001.

17 GUYTON \& HALL. Tratado de Fisiologia Médica, $9^{\text {a e }}$ ed. Rio de Janeiro. RJ. Cap. 36, p. 421-426, 1997.

18 HOFMANN, H \& BON, C. Blood Coagulation Induced by the Venom of Bothrops atrox. 2. Identification, Purification, and Properties of Two Factor $X$ Activators. Biochemistry, 26 p.780-787, 1987. JIN, Y.; LU, Q-M.; CHEN, R-Q.; WU, J-B.; XIONG, Y-L. - Molecular characterization of a weak fibrinogen-clotting enzyme from Trimeresurus jerdonii venom. Toxicon, $45 p-353-360,2005$. 
20 JOSEPH, J. S., CHUNG, M.C.M., JEYASEELAN, K., \& KINI, R.M. Amino Acid Sequence of Trocarin, a Prothrombin Activator from Tropidechis carinatus Venom: Its Structural Similarity to Coagulation Factor Xa. Blood, 94,(2) p.621631. July $15,1999$.

21 JOSEPH, J. S., CHUNG, M.C.M., MIRTSCHIN, P.J., \& KINI, R.M. Effect of snake venom procoagulants on snake plasma: implications for the coagulation cascade of snakes. Toxixon 40, p- 175-183, 2002

22 KINI, R.M. The intriguing world of prothrombin activators from snake venom. Toxicon 45 p-1133-1145, 2005.

23 LAEMMLI, U.K.-Cleavage of structural proteins during the assembly of the head of bacteriophage T4. Nature, $\underline{227}$ p.680-685, 1970.

24 LAING, G.D., COMPTON, S.J., RAMACHANDRAN, R., FULLER, G.L.J., WILKINSON, M.C., WAGSTAFF, .C., WATSON, S.P., KAMIGUTI, A.S., THEAKSTON, R.D.G., SENIS, Y.A. Characterization of a novel protein from Proatheris superciliaris venom: Proatherocytin, a $34-k D a$ platelet receptor PAR1 agonist. Toxicon 46, p- 490-499, 2005.

25 LIN, D.; TABB, D.L.; YATES III, J.R. "Large-scale protein identification using mass spectrometry" Biochimica et Biophysica Acta 1646 p.1-10, 2003.

LIZANO S, LAMBEAU G, LAZDUNSKI M.Cloning and CDNA sequence analysis of Lys (49) and Asp(49) basic phospholipase $A(2)$ myotoxin isoforms from Bothrops asper. Int. J. Biochem Cell Biol.33(2) p.127-32, 2001.

27 MATSUI, T., FUJIMURA, Y., TITANI, K. Snake venom proteases affecting hemostasis and thrombosis. Biochimica et Bioprysica Acta 1477 p- 146-156, 2000 .

28 MARCKLAND F.S. Snake venom and hemostatic system. Toxixon $36, n 12$ p1749-1800, 1998. 
29 MONTEIRO, R.Q, ZINGALI, R.B.-Bothrojaracin, a proexosite I ligand, inhibits factor Va-accelerated prothrombin activation.Thromb Haemost. 87(2) p.288-293, 2002.

30 MOURA Gonçalves, J. \& LAURA GOUVÊA VIEIRA - Estudos sobre venenos de serpentes Brasileiras. An. Da Acad. Brasileira de Ciências. p-141-150, t. XXII n.1, 1950.

31 NAHAS.L; KAMIGUTI, A.S. \& BARROS, M.A.R. Thrombin-like and factor X Activator components of Bothrops snake venoms. Thromb Haemost 2 (41) p314-328, 1979.

NASCIMENTO, N. "Estudo comparativo entre crotoxina nativa e irradiadaAspectos bioquímicos e farmacológicos" 1991 Dissertação (Mestrado) Instituto de Pesquisas Energéticas e Nucleares, São Paulo.

OLIVEIRA, M.R.A.A. Hematologia Básica, American Méd Editora Ltda. São Paulo, SP. cap.4, p-161, 1998.

34 POLETI, E.F. - Síntese, estudos biológicos e conformacionais de análogos da angiotensina ll e bradicinina contendo um marcador de :om estrutura do tipo pirrolidina. 2006 Tese (Doutorado) Universidade Federal de São Paulo - Escola Paulista de Medicina, São Paulo.

35 PRADO-FRANCESCHI, J. \& VITAL-BRAZIL, O. - Convulxin, a new toxin from the venom of the South Americam Rattlesnake Crotalus durissus terrificus. Toxicon 19. $p-875-887,1981$.

36 RAO, V.S.; KINI, R.M. - Pseutarin C, a prothrombin activator from Pseudonaja textilis venom: Its structural and functional similarity to mammalian coagulation factor Xa-Va complex. Thromb Haemost 88. p -611-619, 2002. 
37 RAW, I.; ROCHA, M.C.; ESTEVES, M.I.; KAMIGUTI, A.S. Isolation and characterization of a thrombin-like enzyme from the venom of Crotalus durissus terrificus. Braz. J. Med. Biol. Res.19 p.333-338, 1986.

38 RISSI-SILVA, M.E. Análise Proteômica do Complexo Salivar da Sanguessuga Haementeria depressa. 2004. Tese (Doutorado) - Instituto de Ciências Biomédicas, São Paulo.

39 ROSING, J.; TANS, G. - Structural na funcional properties of snake venom prothrombin activator. Toxicon 30. p-1515-1527, 1992.

40 RUCAVADO A, SOTO M, KAMIGUTI AS, THEAKSTON RD, FOX JW, ESCALANTE T, GUTIERREZ JM. - Characterization of aspercetin, a platelet aggregating component from the venom of the snake Bothrops asper which induces thrombocytopenia and potentiates metalloproteinase-induced hemorrhage. Thromb Haemost. 85(4) p.710-5, 2001.

41 SANO-MARTINS, I.S., TOMY, S.C., CAMPOLINA, D., DIAS, M.B., CASTRO, S.C.B., SOLSA E SILVA, M.C.C., AMARAL, C.F.S., REZENDE, N.A., KAMIGUTI, A.S., WARREL, D.A., THEAKSTON, R.D.G. Coagulopathy following lethal and non-lethal envenoming of humans by the South American rattlesnake (Crotalus durissus) in Brazil. Q.J. Med; 94 p. 551-559. 2001. multifaceted analysis of viperid snake venoms by two-dimensional gel electrophoresis: An approach to understanding venom proteomics. Proteomics, 5 p.501-510, 2005.

SERRANO, S.M.T., MAROUN R.C., Snake venom serine proteinases: sequence homology vs. Substrate specificity, a paradox to be solved. Toxicon, 45 p.11151132, 2005. (enzima trombina simile) do Veneno da Cascavel Brasileira, Crotalus 
durissus terrificus. 2004. Dissertação (Mestrado)-Instituto de Pesquisas Energéticas e Nucleares, São Paulo. M., GUARNIERI M. C., LAZZARI M. A., SAMPAIO C. A. M., POZNER R. G., VENTURA J.S., HO P.L.. A prothrombin activator from Bothrops erytromelas (jararaca-da-seca) snake venom: characterization and molecular cloning. Biochem. J. 369 p.129-139, 2003. ofídicos. Memórias do Instituto Butantan, vol. XII p- 505-513, 1938.

47 SLOTTA, K. H.; FRAENKEL-CONRAT, H. Two Active Proteins from Rattlesnake Venom. Nature, 3587 p-213. Julho de 1938.

STOCKER K.; FISCHER H.; MEIER J.- Thrombin-like snake venom proteinases. Toxicon, 20(1) p. 265-273, 1982.

STOCKER,K. F.-Medical of snake venom proteins CRC press. Composition of snake venoms. P. 34-50. 1990.

50 TAKEDA, A.K.; BARBOSA, S.F.C.; COSTA, L.M. \& ADELINO, M.G.F. Fracionamento do veneno de Crotalus durissus terrificus por cromatografia de exclusão molecular. Rev. Inst. Med. Trop. São Paulo, 27 (3) p - 115 122, 1985

51 TEMPONE AG, ANDRADE HF JR, SPENCER PJ, LOURENCO CO, ROGERO JR, NASCIMENTO N. Bothrops moojeni venom kills Leishmania spp. with hydrogen peroxide generated by its L-amino acid oxidase. Biochem Biophys Res Commun. 280(3) p.620-624, 2001.

52 THEAKSTON, RGD \& KAMIGUTI, AS.-A list of animal toxins and some other natural products with biological products. Toxicon, p. 579-651,2002.

53 TOWBIN, H., STAEHELIN, T., \& GORDON, J.. Electrophoretic transfer of proteins from polyacrylamide gels to nitrocellulose sheets: Procedure and some 
applications. Biochemistry Proc. Natl. Acad. Sci. USA. 76(9): p. 4350-4354, September 1979 .

54 VARGAFTIG, B. B ; PRADO FRANSCESCHI, J; CHIGNARD. M.; LEFORT, J.; MARLAS, G. Activation of Guinea-pig platelets inducec by convulxin, a substance extracted from the venom of Crotalus durissus cascavella. European Journal of Pharmacology, 68 p- 451-464, 1980.

55 VARGAFTIG, B. B.; JOSEPH, D.; WAL, F.; MARLAS, G.: CHIGNARD, M.; CHEVANCE, L. G. Convulxin induced activation of intact and of thrombin degranulated rabbit platelets: specific crossed desensitization with collagen. Eur. J. Pharmacol., 92 p. 57 - 68, 1983.

56 VITAL BRAZIL, O.; PRADO FRANSCESCHI, J,; EZEQUIEL WAISBICH. Pharmacology of crystalline Crotoxin. I. Toxicity. Mem. Inst. Butantan 33(3) p973-980, 1966.

57 VITAL BRAZIL, O.; PRADO FRANSCESCHI, J,; EZEQUIEL WAISBICH. Fator neurotóxico na peçonha da Crotalus durissus terrificus diferente da crotoxina e

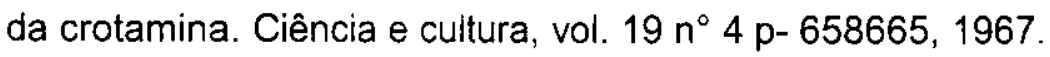

VITAL BRAZIL, O.; BARBARA EXCELL. Action of crotoxin and crotamin from the vrnom of Crotalus durissus terrificus (South American rattlesnake) on the frog neuro-muscular junction. Physiological society, p-34 e35, 1970.

59 VITAL-BPAZiL, O. Veneno ofídico neurotóxico. Rev. Ass. Med. Brasil, 26 (6) p. 218. unho 1980.

i) viAL-BRAZIL, O.-Pharmacology of crotamine. Mem. Inst. Butantan, 52 (supl): p.23-24, 1990.

61 WEStermeIER, R; NAVEN, T. Proteomics in Practice. Weinneim, Wiley-VCH, 2002. 
62 ZAMUNER, S.R, TEIXEIRA, C.F.-Cell adhesion molecules involved in the leukocyte recruitment induced by venom of the snake Bothrops jararaca. Mediators Inflamm. 11(6) p.351-357, 2002. 
